\title{
Stirling Engine Research at National and University Laboratories in Japan
}

\author{
G. J. Hane \\ R. A. Hutchinson
}

September 1987

Prepared for the U.S. Department of Energy under Contract DE-AC06-76RLO 1830

Pacific Northwest Laboratory

Operated for the U.S. Department of Energy

by Battelle Memorial Institute

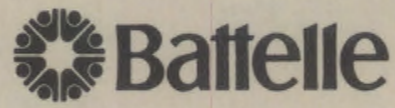




\section{DISCLAIMER}

This report was prepared as an account of work sponsored by an agency of the United States Government. Neither the United States Government nor any agency thereof, nor Battelle Memorial Institute, nor any of their employees, makes any warranty, expressed or implied, or assumes any legal liability or responsibility for the accuracy, completeness, or usefulness of any information, apparatus, product, or process disclosed, or represents that its use would not infringe privately owned rights. Reference herein to any specific commercial product, process, or service by trade name, trademark, manufacturer, or otherwise, does not necessarily constitute or imply its endorsement, recommendation, or favoring by the United States Government of any agency thereof, or Battelle Memorial Institute. The views and opinions of authors expressed herein do not necessarly state or reflect those of the United States Government or any agency thereof, or Battelle Memorial Institute.

\section{PACIFIC NORTHWEST LABORATORY operated by \\ BATTELLE MEMORIAL INSTITUTE \\ for the \\ UNITED STATES DEPARTMENT OF ENERGY under Contract DE-AC06-76RLO 1830}

\begin{tabular}{|c|c|}
\hline \multicolumn{2}{|c|}{ Printed in the United States of America } \\
\hline \multirow{2}{*}{\multicolumn{2}{|c|}{$\begin{array}{l}\text { Available from } \\
\text { National Technical Information Service }\end{array}$}} \\
\hline & \\
\hline \multicolumn{2}{|c|}{ United States Department of Commerce } \\
\hline \multicolumn{2}{|c|}{5285 Port Royal Road } \\
\hline \multicolumn{2}{|c|}{ Springfield, Virginia 22161} \\
\hline \multirow{2}{*}{\multicolumn{2}{|c|}{$\begin{array}{l}\text { NTIS Price Codes } \\
\text { Microfiche A01 }\end{array}$}} \\
\hline & \\
\hline \multicolumn{2}{|c|}{ Printed Copy } \\
\hline & Price \\
\hline Pages & Codes \\
\hline 001-025 & $\mathrm{A} 02$ \\
\hline 026-050 & $\mathrm{A} 03$ \\
\hline 051-075 & A04 \\
\hline 076-100 & A05 \\
\hline $101-125$ & $A 06$ \\
\hline $126-150$ & $\mathrm{~A} 07$ \\
\hline $151-175$ & A08 \\
\hline $176-200$ & 109 \\
\hline 201-225 & A010 \\
\hline $226-250$ & A011 \\
\hline $251-275$ & A012 \\
\hline 276-300 & A013 \\
\hline
\end{tabular}


G. J. Hane

R. A. Hutchinson

September 1987

Prepared for

the U.S. Department of Energy

under Contract DE-AC06-76RLO 1830

Pacific Northwest Laboratory

Richland, Washington 99352 

. . 


\section{PREFACE}

Stirling engines have been received considerable attention in the United States and abroad as a high-efficiency, low-emission, and uniqualy flexible power plant. To date, however, no significant market roles have been filled by stirling prime movers. There are many technical, economic and institutional reasons for this. One key factor is that much of the fundamental engineering science on which the engine's performance depends is still not understood. In addition, components such as bearings, seals, heaters and regenerators still require improvements.

The Japanese, relative latecomers to the technology, have for the last six years focused a strong development effort on two likely Stirling applications. Like other countries' efforts, Japan's documentation of their Stirling engine work does not emphasize fundamental research. This report examines Japan's Stirling engine work, including efforts that are not part of the governmentpromoted program, as well as work that is. All the work takes place at national laboratories or universities. 


\section{ABSTRACT}

Pacific Northwest Laboratory (PNL) reviewed research projects that are related to the development of Stirling engines and that are under way at Japanese national laboratories and universities. The research and development focused on component rather than on whole engine development. PNL obtained the information from a literature review and interviews conducted at the laboratories and universities. The universities have less equipment available and operate with smaller staffs for research than do the laboratories. In particular, the Mechanical Engineering Laboratory and the Aerospace Laboratory conduct high-quality component and fundamental work. Despite having less equipment, some of the researchers at the universities conduct high-quality fundamental research. As is typical in Japan, several of the university professors are very active in consulting and advisory capacities to companies engaged in Stirling engine development, and also with government and association advisory and technical committees. Contacts with these professors and selective examination of their research are good ways to keep abreast of Japanese Stirling developments. 
.

.

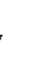


Pacific Northwest Laboratory (PNL) conducted a preliminary review of public-sector Stirling engine research in Japan in support of the U.S. Department of Energy's (DOE's) cooperative research agreement with the International Energy Agency (IEA) on Stirling Engine Technology for Application in Buildings. The IEA was formed to promote international cooperation for developing energy conservation technologies.

To obtain the information on Stirling engine research, PNL conducted interviews and a literature search. The interviews included staff working on Stirling engine research at four national laboratories and four universities in Japan. The review of Japanese literature focused on national laboratory and university work and was extended to include previously unknown publications concerning work performed by Japanese manufacturers and funded by the Japanese government. The manufacturers are developing Stirling heat pump and cogeneration technology as part of a large-scale energy conservation research program, known as the Moonlight Project.

The interviews revealed that, generally, research and development (R\&D) at the national and university laboratories visited focused on component R\&D rather than on whole engine development. Several of the university professors, however, are very active in consulting and advising manufacturers engaged in Stirling engine development, and in government and association advisory and technical committees. As a result, those professors are well informed of the breadth of current Stirling engine research and of plans for new activities.

Although the researchers interviewed are involved in a range of component and supporting research, there are categories of research in which several organizations are active: 1) regenerator development and oscillating flow research, 2) seal development, 3) combustion research, 4) simulation work, 5) novel research, and 6) engine development. Highlights of the research under way in these areas are briefly summarized below, along with results of the literature search conducted. 
REGENERATOR DEVELOPMENT AND OSCILLATING FLOW RESEARCH

Many of the laboratories visited are involved in regenerator R\&D. The R\&D includes studies of regenerator materials and designs as well as "build and test" development of regenerators. At one laboratory, researchers are attempting to better characterize the performance and heat transfer coefficients associated with using foamed metals. One university has been characterizing regenerator performance using foamed materials and wire gauzes, including development of scaling laws for using gauze combinations in a working engine. At another laboratory and at a university, researchers are experimenting with various regenerator materials and designs to arrive at empirical optimal designs.

Research into the effects of oscillating flow is being pursued at three laboratories. At one lab, the work is fundamental and directed at investigating the effects of oscillation on heat transfer through the turbulent boundary layer in a circular tube. Another lab has a facility that simulates flow in one tube of the Stirling engine heater head to enable detailed measurements of flow characteristics. At the third lab, a researcher is assembling a device to investigate the effects of flow oscillation on the regenerator's performance.

\section{SEALS}

The Japanese have done a considerable amount of empirical testing of seal designs and materials. At one lab, researchers are investigating both seal designs and seal materials. They are testing conventional piston and rod seal designs: rib-type seals, lip-type endless seals, and seals with back-up rings. Most of the materials' tests seem to focus on combinations of PFTE and carbon fibers or oils. At another lab, a simple three-ring seal design that is thought to offer low gas leakage and low friction has been patented. Staff at a third lab are conducting piston seal research to assist in developing a $2 \mathrm{~kW}$ stirling engine. 
Combustion research being conducted includes fundamental studies of the combustion process with various burners via laser doppler velocimetry (LDV) measurements and coherent anti-stokes Raman spectroscopy (CARS) experiments. Also, the combustion of biomass is being analyzed, and fluidized-bed combustion experiments are being conducted, as noted under "Novel Research" below.

\section{SIMULATION}

Simulation research is being conducted to some level at all four laboratories visited. At one lab, the researchers have developed a 50 space model of the Stirling engine and are currently working on more simplified models to use interactively with laboratory experiments. They are also discussing the possibility of developing a simple computer-aided design (CAD) model of the Stirling engine. One university professor also mentioned that he would like to begin work on a CAD model of the Stirling engine but is currently limited by funding constraints.

At another $1 \mathrm{ab}$, researchers are very active in modeling the combustion process and then conducting fundamental combustion experiments. A professor from a third lab has conducted overall cycle simulation using a five space model of the Stirling engine.

\section{NOVEL RESEARCH}

In addition to the research under way in the more conventional areas, some researchers are pursuing more novel research into fluidized-bed and biomass combustion and two-phase, two-component mixtures. At one lab, researchers are currently trying to characterize the heat transfer parameters of a fluidized bed applied to the heater head of a Stirling engine. Preliminary experiments show a marked improvement in the heat transfer coefficient. Also, researchers at one university are preparing to conduct fluidized-bed experiments using biomass briquettes.

At another university, researchers are conducting experiments with twophase, two-component Stirling working fluid mixtures to investigate the 
advantages of higher heat transfer from condensation and evaporation. They are investigating air-water and air-freon mixtures.

\section{ENGINE DEVELOPMENT}

The primary engine development work in Japan is carried out by private companies with component R\&D support being provided by national labs. However, several companies are pursuing separate development projects as well as collaborating with key university researchers. Other university researchers maintain an interest in system development but have $1 \mathrm{jttle}$ funding at present. In addition, two research institutes have actively developed engines, one as part of an unsuccessful development program, now finished, and the second with a primary goal of verifying simulation codes with special test engines.

\section{LITERATURE REVIEW}

The literature review indicated that the IEA exchange is a more thorough way of monitoring the Japanese literature than conducting literature reviews on the national data base, Japan Information Center for Science and Technology (JISCT). Such reviews of JISCT, conducted by the Global Competitiveness Council and PNL, have indicated that many of the articles presented at technical meetings and society meetings do not appear in the data base. These articles are often more technically specific than those appearing in the general literature.

The four manufacturers participating in the Moonlight Project are represented in the international literature. These articles typically contain system and some component performance data, although somewhat more detailed articles can be found in the Japanese literature. However, the internationa literature provides a good overview of the work's progress. The best sources are the Intersociety Energy Conversion Engineering Conference (IECEC) and the proceedings from International Stirling Engine Conferences.

The literature indicates that during the first three years of the Moonlight Project, manufacturers were focusing on meeting the mid-program system performance goals. As a result, many of the early articles described system performance. In the past two years, the trend has been toward reporting more 
specific component performance data. Unfortunately, much of the data are still in Japanese.

Data from a mid-project test in 1984 of Stirling engines developed by the manufacturers were published in Japanese, but not in English. A similar end-of-program testing will be conducted late in 1987.

The industrial publications indicate that of the four manufacturers in the Moonlight Project, two have published a few articles, which only broadly discussed component development. The other two manufacturers were better represented with the number of articles published, but both tended to publish articles that were more general when written in English and more componentspecific when written in Japanese. However, this tendency may just be a result of the interests of their audiences. As the component research is completed toward the end of the program late in 1987, more component-specific articles written in English can be expected.

Currently, the largest gap in translated material is in the area of seal research. The companies involved in the Moonlight Project have published little regarding seals. Most of the published work has come from one national lab. There are two programs in seal research, one directed at the mechanical properties of different designs and a second directed toward the research of different materials. To date, both groups of researchers have only published one article in English, but have published at least 13 written in Japanese since 1981. Some of this work is described later in this report.

In university research, there are some gaps in timing and areas of coverage, but this varies greatly with the researchers. Occasionally, researchers will publish first in Japanese in a journal such as the Transactions of the JSME and then have the article translated and published in English in the Bulletin of the JSME. When this is done, the time lag is about eight months. 
•

.

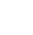


TABLE OF CONTENTS

PREFACE. ........................

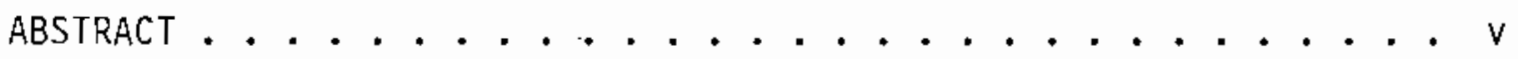
SUMMARY................................... vi REGENERATOR DEVELOPMENT AND OSCILLATING FLOW RESEARCH . . . viii SEALS ........................ ix

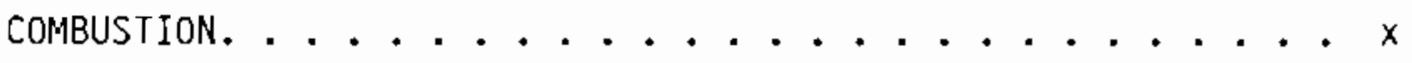
SIMULATION. ............................. NOVEL RESEARCH. ......................... ENGINE DEVELOPMENT. ....................... xi

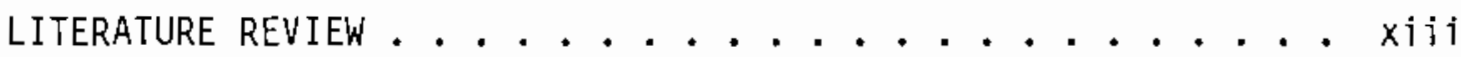

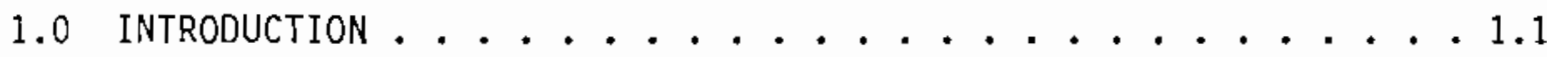

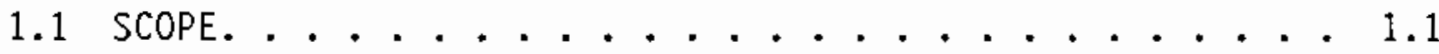

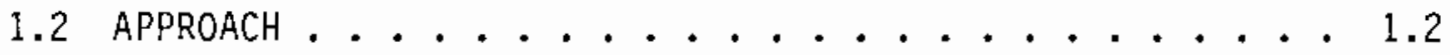

1.3 REPORT CONTENTS. . . . . . . . . . . . . 1.3 2.0 BACKGROUND DESCRIPTION OF INTERVIEW PARTICIPANTS. . . . 2.1

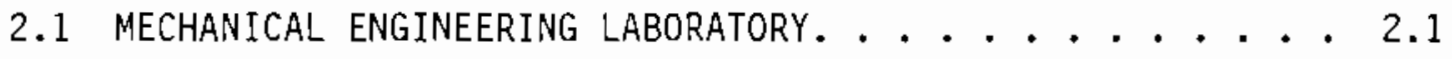

2.2 NATIONAL AEROSPACE LABORATORY. . . . . . . . 2.2

2.3 POLLUTION AND NATURAL RESOURCES LABORATORY ...... 2.3

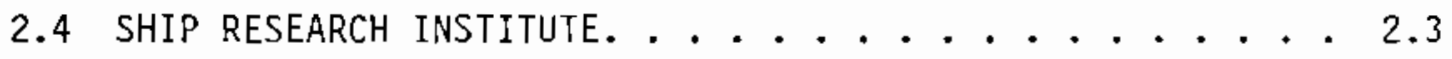

2.5 PROFESSOR ISSHIKI. . . . . . . . . . . 2.4

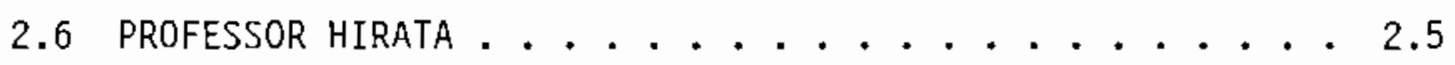

2.7 PROFESSOR YOSHIKI. . . . . . . . . . . 2.5

2.B PROFESSORS MIYABE, TAKAHASHI, AND FUJII. ...... 2.6

2.9 PROFESSOR NAKAJIMA . . . . . . . . . . . . 2.6

2.10 PROFESSOR NISHIMOTO. . . . . . . . . . 2.7 
2.11 JAPAN REFRIGERATION AND AIR CONDITIONING INDUSTRY ASSOCIATION. . . . . . . . . . . . . 2.7

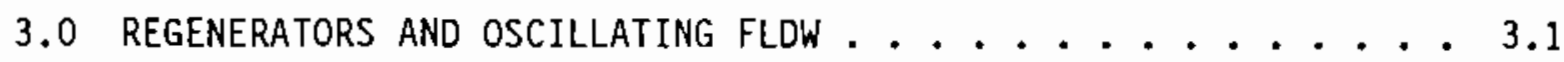

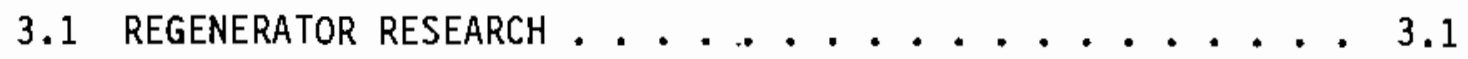

3.1.1 Mechanical Engineering Laboratory....... 3.1

3.1 .2 Professor Isshiki ............. 3.1

3.1 .3 Professor Miyabe. . . . . . . . . . 3.3

3.1.4 Professor Takahashi ........... . . 3.4

3.1.5 Professor Nishimoto ........... 3.5

3.2 OSCILlating FlOW RESEARCH. . . . . . . . . . 3.5

3.2.1 Professor Hirata. . . . . . . . . . 3.5

3.2.2 Professor Yoshiki ........... . . . 3.6

3.3 Literature COMParison. . . . . . . . . . . 3.6

3.3.1 Mechanical Engineering Laboratory ....... . 3.8

3.3.2 Professor Isshiki . . . . . . . . . 3.8

3.3.3 Professors Miyabe and Takahashi ........ 3.8

3.3.4 Professor Hirata. . . . . . . . . . 3.10

3.3.5 Professor Yoshiki ........................

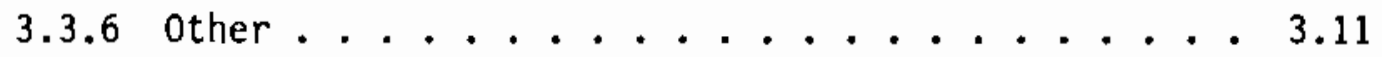

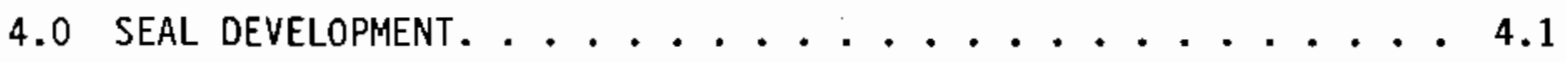

4.1 MECHANICAL ENGINEERING LabORatoRY. .......... 4.1

4.2 PROFESSOR ISSHIKI. . . . . . . . . . . 4.2

4.3 Literature COMPARISON. . . . . . . . . . 4.6

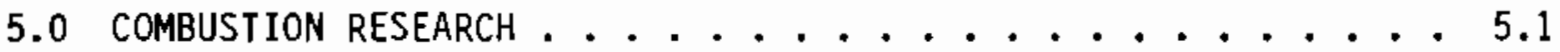

5.1 NATIONAL AEROSPACE LABORATORY ................. 5.1

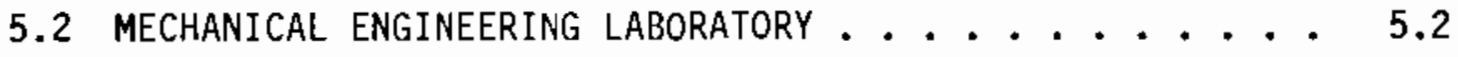

5.3 PROFESSOR ISSHIKI . . . . . . . . . . . 5.2 


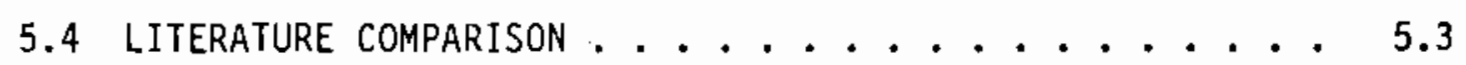

6.0 SimUlation RESEARCH. ....................... 6.1

6.1 MECHANICAL ENGINEERING LABORATORY . . . . . . . 6.1

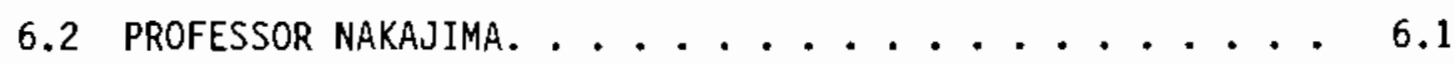

6.3 PROFESSOR YOSHIKI ..................... 6.1

6.4 Literature COMPARiSON . . . . . . . . . . . 6.2

6.4.1 Mechanical Engineering Laboratory. . . . . . 6.2

6.4 .2 Professor Nakajima . . . . . . . . . 6.2

6.4 .3 Professor Yoshiki. ........... 6.3

6.4 .4 other. ................. 6.3

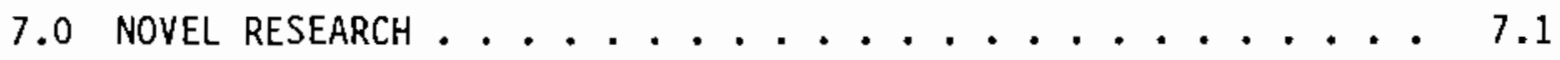

7.1 MECHANICAL ENGINEERING LABORATORY .......... 7.1

7.2 POllution and Natural ResOURCeS laboratory. . . . . 7.1

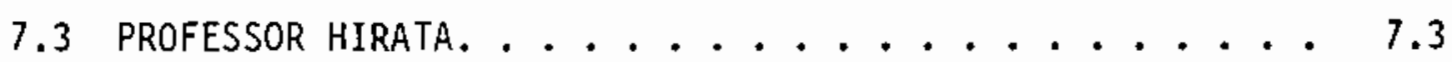

7.4 PROFESSOR NAKAJIMA. . . . . . . . . . . . . 7.4

7.5 PROFESSOR FUJII . . . . . . . . . . . . . . 7.5

7.6 LiteRATURE COMPARISON . . . . . . . . . . 7.5

7.6.1 Mechanical Engineering Laboratory. . . . . 7.5

7.6.2 Pollution and Natural Resources Laboratory . . 7.5

7.6 .3 Professor Hirata . . . . . . . . . 7.6

7.6 .4 Professor Nakajima . . . . . . . . 7.6

7.6 .5 Professor Fujii. . . . . . . . . . 7.7

7.6 .6 other. . . . . . . . . . . . 7.7

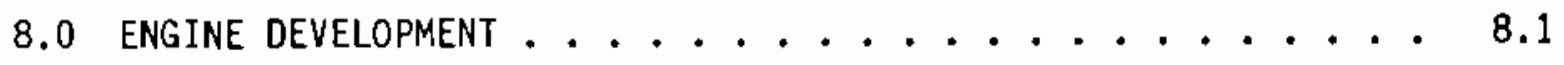

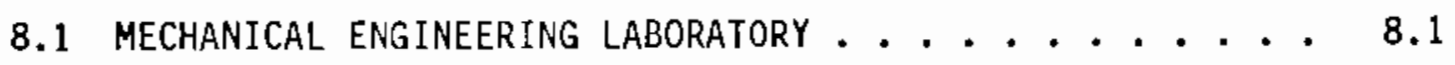

8.2 PROFESSOR ISSHIKI . . . . . . . . . . 8.2 
8.2.1 Tokyo Sanyo. . . . . . . . . . . 8.2

8.2 .2 Sanden . . . . . . . . . . . 8.3

8.2.3 Ship Research Institute. . . . . . . . 8.4

8.3 PROFESSOR NISHIMOTO . . . . . . . . . . . 8.4

8.4 Literature COMPARISON . . . . . . . . . . 8.5

8.4.1 Mechanical Engineering Laboratory. . . . . . 8.5

8.4 .2 Professor Isshiki. . . . . . . . . 8.6

8.4.3 Professor Nishimoto. . . . . . . . . 8.8

8.4 .4 other. . . . . . . . . . . 8.8

9.0 LITERATURE COMPARISON OF PRIVATE SECTOR R\&D. . . . . . . 9.1

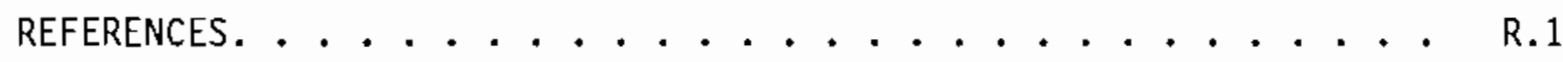
APPENDIX A - ADDRESSES OF INTERVIEW PARTICIPANTS. . . . . . A A.1 APPENDIX B - PERFORMANCE SHEETS FROM MID-PROJECT TEST OF STIRLING ENGINES .................. B. 


\section{FIGURES}

2.1 Summary of Interaction Between NAL and Manufacturers on the Moonlight Stirling Engine Heat Pump Project. . . . . . . . 2.3

3.1 Schematic of the Laboratory Device Used by Professor Yoshiki for Oscillating Flow Experiments . . . . . . . 3.7

3.2 Comparison of Mean Heat Transfer Coefficients Between Wire Gauzes and Foamed Metals ............... 3.9

4.1 Relation Between Wear Loss and Coefficient of Friction with the Distance of Contact............... 4. 4.3

4.2 Relation Between Wear Loss and Surface Roughness . . . . . . 4.4

4.3 Schematic of Seal Testing Apparatus. . . . . . . . . 4.5

4.4 Relation Between Leakage Rate and Time . . . . . . . . . 4.6

4.5 Reiation Between Leakage Rate and Normal Load. . . . . . . 4.7

7.1 Schematic of the Fluidized Bed Heat Exchanger and Measurements of the Heat Transfer Coefficient . . . . . . . . . 7.2 


\subsection{INTRODUCTION}

In May 1986 two Stirling engine researchers from Mechanical Technology, Inc., (MTI) visited manufacturers in Japan who were investing in the development of stirling engine technologies. The MTI researchers noted that although several firms had been or were conducting research into the Stirling engine technology, the strongest programs were found in companies participating in the government-promoted program, Stirling Engines for Wide Use. This program is part of the Moonlight Project, an R\&D program for energy conservation, being administered within the Ministry of International Trade and Industry (MITI) by the Agency for Industrial Science and Technology (AIST). The New Energy Development Organization (NEDO), a combined private/public sector organization whose role is to focus on technology commercializations, also assists in managing the Moonlight Project.

Besides private firms, several national laboratories also are contributing research in the Stirling program, and Stirling engine researchers from universities are providing program guidance. This is the typical division of work in MITI projects. Because the activities of these researchers are key elements in the Japanese program and may provide special data for use in the U.S. Stirling engine-driven heat pump program, Pacific Northwest Laboratory (a) was asked to review their activities. A second objective was to compare the technical literature published in Japanese with that published in English by Japanese researchers. Besides its use in program planning, the knowledge gained was used in support of U.S. activities in the IEA Advanced Heat Pump Implementing Agreement.

\subsection{SCOPE}

The interviews conducted in this study were restricted to researchers in the national and university labs in Japan in order to complement existing information on efforts by Japanese manufacturers. Although some researchers,

(a) Pacific Northwest Laboratory is operated for the U.S. Department of Energy by Battelle Memorial Institute. 
particularly those at universities, are involved in several research areas, the discussions were restricted to their work in Stirling engines. This review was not restricted to participants in the Stirling Engines for Wide Use Program. Because of the influence of this program and past Stirling engine programs, several universities and foundations have also been supporting Stirling engine R\&D. The interviews conducted in this study also covered such work.

The emphasis of the literature comparison was on the articles published in the last five years. Because English language articles are readily accessible to U.S. researchers, this review focuses on drawing comparisons and summarizing the topics covered by articles in Japanese.

Research from four national laboratories was examined:

- Mechanical Engineering Laboratory (MEL)

- National Aerospace Laboratory (NAL)

- Pollution and Natural Resources Laboratory

- Ship Research Institute.

The first three laboratories listed are participating in the Stirling Engines for Wide Use Program. The Ship Research Institute was involved with an earlier government stirling engine research project for marine applications.

Because of their involvement with Stirling engine research, the following professors were interviewed:

- Naotsugu Isshiki - Nihon University

- Masaru Hirata - University of Tokyo

- Haruo Yoshiki - Institute of Industrial Science, University of Tokyo

- Hiyeda Miyabe - Meiji University

- Shintaro Takahashi - Meiji University

- Iwane Fujii - Meiji University

- Naomasa Nakajima - University of Tokyo

- Keijchi Nishimoto - Kanazawa University

In addition, representatives of the Japan Industrial Refrigeration Associaticn were interviewed to discuss the newly formed Japan Heat Pump Center.

\subsection{APPROACH}

The laboratories and researchers visited were identified through several sources, including 1) an unpublished preliminary review of Stirling engine research in Japan, conducted by the Global Competitiveness Council of Boston, 
2) a review of recent literature published in Japan, 3) discussions with a Stirling engine research program manager at MITI, and 4) discussions with Stirling engine researchers. A report developed for the IEA gives considerable background on MITI research activities, as well as work in Sweden and the United States (A. D. Little 1987).

In the interviews, three general issues were discussed: 1) the organization of research at the laboratory, 2) current activities and areas of specialization, and 3) the extent of publication. The discussion of laboratory organization included the range and division of Stirling engine R\&D and the number of staff conducting the work. The discussion of current activities and specialization included the breadth and status of current projects. This included questions such as: What type of research is being pursued? What laboratory equipment is used? and what types of results are being seen? The extent of publication included discussions of past and planned publications in both Japanese and English.

The Japanese-language literature was identified through information the Japanese submitted to the IEA on past Stirling projects, through a literature search of the Japan Information Center for Science and Technology data base, and through publications gathered during the interviews.

\subsection{REPORT CONTENTS}

Chapter 2.0 presents background information on each university, lab and professor included in this study and on the Japan Heat Pump Center. Chapters 3.0 through 8.0 present the results of the interviews and literature search according to the following categories:

- regenerator and oscillating flow development (Chapter 3.0)

- seal development (Chapter 4.0)

- combustion (Chapter 5.0)

- simulation work (Chapter 6.0)

- novel research (Chapter 7.0)

- engine development (Chapter 8.0).

In each chapter, the interview results are followed by the literature comparison. In a few cases, data from specific papers are presented. These papers represent gaps in the English language literature and have been selected 1.3 
because they are the most important or most representative. Chapter 9.0 presents the literature comparison of private-sector R\&D. Appendix A lists addresses for the researchers interviewed. Appendix B contains annotated copies of the performance sheets from the 1984 mid-project test of Stirling engines. 


\subsection{BACKGROUND DESCRIPTION OF INTERVIEW PARTICIPANTS}

Four national laboratories were targeted for the interviews because of their involvement with Stirling Engine Research:

- Mechanical Engineering Laboratory (MEL)

- National Aerospace Laboratory (NAL)

- Pollution and Natural Resources Laboratory

- Ship Research Institute.

The following professors were interviewed:

- Naotsugu Isshiki - Nihon University

- Masaru Hirata - University of Tokyo

- Haruo Yoshiki - Institute of Industrial Science, University of Tokyo

- Hiyeda Miyabe - Meiji University

- Shintaro Takahashi - Meiji University

- Iwane Fujii - Meiji University

- Naomasa Nakajima - University of Tokyo

- Keiichi Nishimoto - Kanazawa University.

In addition, representatives of the Japan Industrial Refrigeration

Association were interviewed to discuss the newly formed Japan Heat Pump Center (JHPC).

Although the industrial participants in the MITI Stirling Engines for Wide Use Project were not interviewed, the four participants are listed here and mentioned often in the text because university professors assist then in various ways. All are developing Kinematic (crank) Stirling engines:

- Mitsubishi Electric Corporation - $3 \mathrm{~kW}$ displacer-type engine

- Toshiba Electric Corporation - $3 \mathrm{kw}$ two-piston engine

- Aisin Seiki - $30 \mathrm{kw}$ swash-plate engine

- Tokyo Sanyo - $30 \mathrm{~kW}$ double-crank engine.

Background information on the four labs, the eight professors, and the IHPC is presented below.

\subsection{MECHANICAL ENGINEERING LABORATORY}

The Mechanical Engineering Laboratory is located in the Tsukuba Science Park about two hours north of Tokyo. Iwao Yamashita, head of the Energy Conversion Section, apparently coordinates most of the Stirling engine research 
at the laboratory: Yukio Yamada is responsible for representing the MEL on the IEA agreement; and Dr. A. Tanako is the principal researcher conducting the mechanical testing of seals.

Most of the Stirling engine research at the MEL is being conducted in the Energy Engineering Department, which is composed of five divisions: 1) Energy Conversion, 2) Thermal Efficiency, 3) Combustion, 4) Fluid Dynamics, and 5) Property Analysis. In addition to the work in this department, some research on seal materials is being conducted in the Tribology Division of the Materials Engineering Department.

of the three national labs involved in the Stirling Engine effort in the Moonlight Project, this lab is the most active in that research. Generally, the MEL laboratories are extensive and seem to have more equipment available than the other labs visited. The MEL has 10 to 12 researchers involved in the Stirling engine research, but no technicians, because of budget restrictions and the nature of their work.

The MEL conducted the first of two program technical evaluations of the Stirling Engines for Wide Use Project in 1984. Each of the four manufacturers brought engines to the MEL facility, and the entire Stirling engine team at the MEL participated in the review. The results have been published in Japanese. Dr. Yamashita has prepared a critical technical review of that evaluation, which he planned to publish in Japanese as a MEL laboratory review. The next and final review will occur at the end of 1987.

\subsection{NATIONAL AEROSPACE LABORATORY}

Staff at the NAL conduct supporting combustion research in the Moonligrt Project's Stirling Engine Heat Pump Project. The objectives of this effort are 1) to provide design data on the high-intensity, low-emission combustor for Stirling engines, and 2) to develop assessment technology for combustion performance and exhaust emissions. This work is supported by seven laboratory researchers and four students. Because all of this work is funded by MITI through the Moonlight Project, the staff will have to revert to a lower level of funding provided by the laboratory when the project ends. 
To transfer the NAL's research results to the private sector, several mechanisms are used: 1) researchers from manufacturers conduct work at the $1 a b ; 2)$ periodic meetings are held with manufacturers; 3 ) general meetings are held by NEDO/MITI; and 4) planning and assessment meetings are sponsored by MITI.

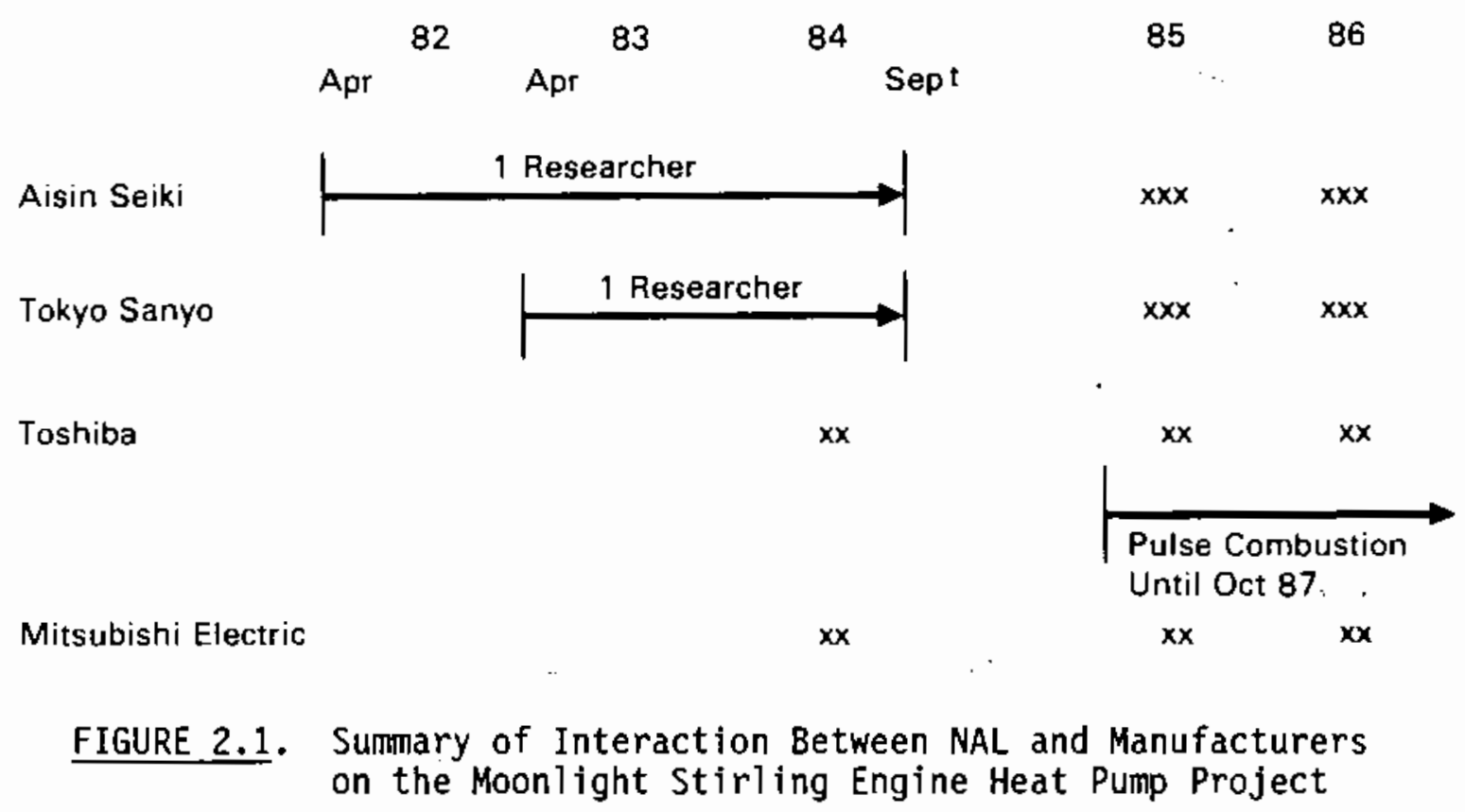

\subsection{POLLUTION AND NATURAL RESOURCES LABORATORY}

The Pollution and Natural Resources Laboratory is the third national lab involved in the Moonlight Project. However, compared with the Mechanical Engineering Laboratory and the National Aerospace Laboratory, this lab's level of Stirling engine research is low. Most of the research is conducted by Dr. Ohyanagi, who has been focusing on the combustion of biomass and alternative fuels for about two years.

\subsection{SHIP RESEARCH INSTITUTE}

The Ship Research Institute is located on the outskirts of Tokyo. Its research on Stirling engines began over 10 years ago, in 1977, with the Marine Stirling Project sponsored by the Ministry of Transportation. Currently at 
the Ship Research Institute, Stirling engine research involves three fulltime staff, one graduate student, and two part-time technicians. Staff time is split fairly evenly between two principal projects: a private Tokyo Sanyo 2 kW Stirling engine project and general research using an old T-type Stirling engine developed in earlier work for test purposes. The Ship Research Institute is also supplying some funds for research on combustion-controlled power control systems.

\subsection{PROFESSOR ISSHIXI}

Professor Isshiki is one of the most active Stirling engine researchers in Japan. Much of his recent work was reported at the Third International Stirling Conference in Rome, Italy, in June, 1986. Professor Isshiki is the Chairman of the Fourth International Stirling Engine Conference, scheduled for 1988 in Tsukuba, Japan. He has recently retired as a professor from Tokyo Institute of Technology and now teaches at the private Nihon University and consults for two companies, Tokyo Sanyo and Sanden. He also has an office and laboratory at the Ship Research Institute.

Professor Isshiki does not specialize in any particular aspect of the Stirling engine, but rather is most interested in developing the system as a whole. His approach seems to be very empirical. He is not carrying out any fundamental studies, and the computer analyses that he is associated with are developed by students for general cycle studies.

Professor Isshiki has organized and is chairman of High Performance Stirling Engine Scientific Association, whose members represent most of the organizations in Japan active in or interested in stirling engine research and development. The association has 30 industrial members and 12 representatives from universities and government organizations. The industrial members pay dues to help support the association.

The association has been meeting about every other month since the beginning of 1986. At each meeting one or two of the members are requested to present and discuss their stirling engine work. Professor Isshiki is trying to promote the association; his underlying philosophy is that because the 
Stirling engine will require a significant amount of development before it is successfully commercialized, the Stirling engine community in Japan should be active in assisting each other. He notes, however, that certain companies that might feel closer to commercialization, such as Aisin Seiki, are somewhat guarded with their information.

\subsection{PROFESSOR HIRATA}

Dr. Hirata is associated with the Mechanical Engineering Department at the University of Tokyo and leads one of the university's three groups of researchers at Tokyo who are involved in work relevant to Stirling engines. Assisting him in his laboratory are four graduate students and an Associate Professor, Dr. Kasagi (who studied under Robert Moffatt a well-known heat transfer instrumentation specialist at Stanford University).

The research conducted in Dr. Hirata's laboratory tends to be fundamentai and is funded by the university (e.g., the Ministry of Education) rather than by the Moonlight Project. However, Dr. Hirata is chaiman of the advisory committee for the Stirling Engine for Wide Use Project. The committee has influence over the work's technical content and the project's schedule. The comittee also participates in the project's annual review conference.

Dr. Hirata also is promoting a follow-on project that he envisions taking two directions. First, he would like to incorporate free-piston research into the Stirling Engine for wide Use Project. He feels that such research would give the project some sense of "newness" that would make it more attractive for MITI support. Secondly, he wants to continue many of the current development projects. Again, this would be to gain support. He noted that to realize this plan, active early promotion was required.

\subsection{PROFESSOR YOSHIKI}

Professor Yoshikj conducts his research at the Institute of Industrial Science, which is separated from the main Tokyo University campus. He is assisted by a lab technician and several graduate students. 
Professor Yoshiki's research into Stirling engines began with the first Ministry of Transportation Stirling engine project in 1977, which focused on marine applications. He was involved both with the effort to predict Stirling engine performance and with an analysis to predict the heater's performance. After this first government projected ended in 1981, Professor Yoshiki contirued his research in two areas: developing a five-space model of the Stirling engine and analyzing oscillating flow. He completed his development of the five-space model and described it in Japanese publications. Currently, he is focusing on analyzing oscillating flow.

\subsection{PROFESSORS MIYABE, TAKAHASHI, AND FUJII}

These professors, located at Meiji University, are known for fundamental studies of Stirling engine components and for the application of solar energy. The researchers at Meiji have been involved with developing Stirling engine technologies since the Marine Stirling Project. Since that project ended in 1981, most of the Stirling engine research has been supported by Meiji University, with various manufacturers supplying pieces of equipment. Each professor has his own laboratory, his own set of students to assist with the research, and his own speciality:

- Professor Miyabe specializes in the analysis of regenerators.

- Professor Takahashi specializes in the analysis and simulation of fluid flow, with particular application to Stirling engines.

- Professor Fuji $i$ focuses on investigating the application of solar energy to Stirling engines.

\subsection{PROFESSOR NAKAJIMA}

Professor Nakajima is associated with the University of Tokyo and has been involved in a range of experiments with Stirling engines. His early work in the late 1970's was directed toward component, notably heater head, studies. Subsequently, he worked with Professors Azetsu and Hirata at Tokyo University in developing a five-space computer model of the engine. Dr. Azetsu later took this experience to the MEL, where he developed a 50 space computer mode 1 . 


\subsection{PROFESSOR NISHIMOTO}

Professor Nishimoto has conducted Stirling engine research in his laboratory at Kanazawa University for several years. His earlier work focused on characterizing different regenerator materials. Currently, however, Professor Nishimoto indicated that the extent of his Stirling engine research has decreased. At the time of the interview his current activity was to run full engine tests to determine how to continue to improve cycle efficiency. He is assisted in the research by another faculty member and two students. All of the funding for the research comes from the university.

\subsection{JAPAN REFRIGERATION AND AIR CONDITIONING INDUSTRY ASSOCIATION}

Mr. Miura and Mr. Igarashi were interviewed at the Japan Refrigeration and Air Conditioning Industry Association (JRIA), primarily to obtain information on the newly formed Japan Heat Pump Center (JHPC). Mr. Miura seems to be the principal person at JRIA involved with the NEDO Stirling Engine Heat Pump Project as well as the IEA Heat Pump Center. Mr. Igarashi is retired from the Agency of Industrial Science and Technology (AIST) at MITI and is the General Manager of the JHPC. The President of the JHPC is a Vice President of Tokyo Electric, M. Iwasa. The two vice presidents are the President of the JRIA and a vice president from Toshiba, E. Yoshida.

The JHPC is being formed primarily to coordinate information flow and to some extent the management of heat pump research in Japan. JRIA was assisting several organizations, notably MITI, in administering heat pump projects. However, as the activities grew, JRIA saw the need to establish a separate organization that would administer an even greater scope of activities. JHPC was established with an initial budget of $300 \mathrm{million}$ yen/year (about $\$ 2 \mathrm{millio}$ : at today's exchange rate). JRIA will act as the Secretariat for the JHPC, but one-third of the funding comes from MITI (which is not directly involved in managing the center) and the remaining two-thirds from dues paid by private organizations.

Currently, 50 nongovernmental organizations are involved in supporting the JHPC. These include manufacturers, gas companies, electric utilities, 
construction companies, banks and university laboratories. Of these 50 organizations 24 are represented in the JHPC Board of Directors. Nine of these are manufacturing companies, 2 are gas companies, and 4 are banks. The 24 organizations are listed below:

- Shinohara Manufacturing

- Osaka Gas

- Ohbayashi Group (Construction)

- Kashima Construction Co.

- Kansai Electric Power

- Kumagai Group

- Sanyo Electric

- Shimizu Construction Co.

- Sumi tomo Bank

- Duijchi Kangyo Bank

- Kaikin Industries

- Taisei Construction Co.
- Takenaka Construction Co.

- Central Electric Power

- Tokyo Gas

- Tokyo Electric Power

- Toshiba

- Hitachi Manufacturing

- Maekawa Manufacturing

- Matsushita Electric

- Mitsubishi Electric

- Mitsui Bank

- Mitsubishi Bank

- JRIA

The stated goals of the center are rather broad. The JHPC will promote the R\&D of heat pump components and advance international cooperative research of heat pump technologies. To achieve these goals, eight work elements define the scope of JHPC activities:

1. research and develop fundamental heat pump component technologies

2. conduct experimental research of heat pump technologies

3. conduct international cooperative research on heat pumps

4. conduct international exchanges on heat pumps

5. research ways to establish evaluation standards and measure heat pump efficiency

6. collect and offer information on heat pump technologies

7. disseminate knowledge on heat pump technologies

8. perform other work necessary to help the organization achieve its goals.

Finally, the JHPC will assist the MITI with the IEA Stirling Engine Heat Pump Agreement. MITI will still act as the point of contact and organization responsible for the Japanese commitment, but much of the actual administrative work will be conducted by the JHPC. This arrangement resembles the support contracts issued by the DOE and other U.S. federal agencies. 


\subsection{REGENERATORS AND OSCILLATING FLOW}

Regenerator research is being conducted at MEL and by Professors Isshiki, Miyabe, Takahashi, and Nishimoto. Research into the physics of oscillating flow is primarily being pursued by Dr. Hirata and Professor Yoshiki. Both sets of researchers have constructed flow test rigs, but the former emphasizes empirical tests while the latter is doing basic research. The work of each is discussed in the sections below, followed by the literature comparison.

\subsection{REGENERATOR RESEARCH}

Japanese researchers have noted that regenerators are very expensive but a key factor in determining Stirling engine performance, so they perform a variety of regenerator research.

\subsubsection{Mechanical Engineering Laboratory}

At the MEL, regenerator testing is currently focusing on evaluating foamed or sponge metals as the matrix material. An article describing this work was presented at the Third International Stirling Engine Conference in June 1986 (Tanaka and Chisaka 1986). Initial experiments show the performance of this material to be about equal to that of wire mesh. Unfortunately, commercially available foam metal is not as dense as needed. The foam metal was therefore compressed, but it has not been determined whether this compression adversely affects its heat transfer characteristics. Professor Miyabe at Meiji University noted that pressing distorts the material's structure and that a much better alternative would be to manufacture a more dense material. The MEL researchers currently are more precisely evaluating the heat transfer coefficient of the material.

\subsubsection{Professor Isshiki}

Professor Isshiki is conducting regenerator research in his consulting roles to both Tokyo Sanyo and Sanden (private work not connected to the Moonlight Project) and in his work at the Ship Research Institute. Each is discussed in the following sections. 


\section{Regenerator Research for Tokyo Sanyo}

For Tokyo Sanyo, Professor Isshiki is developing a $2 \mathrm{~kW}$ Stirling engine for the home heat pump and air conditioning market. Staff from Tokyo Sanyo consult with Professor Isshiki on the engine's development, but at the time of the interviews, decisions seem to have been largely left to Professor Isshiki and staff at the Ship Research Institute.

Professor Isshiki feels that the major problem with the $2 \mathrm{KW}$ engine is improving the regenerator's efficiency. He plans to do this by changing both the regenerator heat transfer material and the regenerator design. Currently, the regenerator is a series of pipes that are positioned around the circumference of the cylinder. The pipes run from the cooler below all the way up to the top of the heater head. Designing the pipes to extend high into the heater head reduced much of the regenerator effectiveness and added unwanted dead space to the regenerator. He feels this will require a redesign, but he did not describe the alternatives.

For the heat transfer material in the regenerator, Professor Isshiki's staff had been using small semi-circular steel chips. The chips are used instead of balls because of the larger surface area available. Currently, he is testing wire fibers as the regenerator material, but apparently the effectiveness of the regenerator is not as high as it is with the chips. Professor Isshiki feels that the ball chips might be a good ultimate material.

Professor Isshiki has also been advocating a regenerator design that would use many small tubes connecting the heater and the cooler. Sanden has apparently said such a regenerator would not be expensive to produce. Whether this design would also be appropriate for the Tokyo Sanyo design is not clear.

\section{Regenerator Research for Sanden}

Professor Isshiki and his laboratory staff at Nihon University are responsible for helping to develop the seals, the regenerator, and the heater head for a Sanden engine based on existing Sanden wobble-plate drive technology (used in a Sanden compressor). Sanden is pursuing the design, without MITI funding, because they feel it will be inexpensive to manufacture. No expensive alloys are used because the heater head is stainless steel. The engine is 
still in the early stages of development with low thermal and mechanical efficiencies.

They have had a series of problems with the engine. One of the problems is that the regenerator is not providing the desired efficiency. As mentioned earlier, Professor Isshiki is investigating a design using many small tubes through which the gas flows.

\section{Regenerator Research at the Ship Research Institute}

Research on Stirling engines at the Ship Research Institute began over 10 years ago, in 1977, with the Marine Stirling Project sponsored by the Ministry of Transportation. That project apparently had two stages: one involving the development of a T-type Stirling engine largely for testing, and the second involving a very ambitious effort to develop a $200 \mathrm{hp}$ marine Stirling engine with a $155 \mathrm{~cm}$ diameter piston. The second effort failed due to technical problems, including excessive seal friction at the piston shaft.

Although the T-type Stirling engine is quite old and is not being developed for commercialization, it is still regularly used for component and regenerator testing. The researchers are primarily interested in testing different heater and regenerator types. They are currently looking at different stainless steel tube and plate-fin heaters, measuring the flow resistance and heat transfer. In the case of regenerators they are testing various particles and balls as regenerator material.

Professor Isshiki noted that relatively large steel balls, about $4 \mathrm{~mm}$ in diameter, seemed to be performing better than wire mesh for the regenerator because they reduce dead space and flow resistance. To improve overall performance Professor Isshiki said he was favoring a big regenerator with less dead space and a small flow resistance.

\subsubsection{Professor Miyabe}

Professor Miyabe from Meiji University focuses his research on the performance of various regenerator designs. He experiments with different combinations of stainless steel wire meshes in reciprocating flow. He is comparing experimental results of performance in an operating cycle with those 
predicted by a computer simulation. In a paper presented at the 1982 Intersociety Energy Conversion Engineering Conference (IECEC), Professor Miyabe correlated the effect on flow friction and heat transfer coefficient of varying the size and depth of the packed wire screens in steady-flow tests (Miyabe, Takahashi and Hamagnchi 1982). He suggested that by using the empirical relations developed, it is possible to predict the performance of any size or number of wire screens.

In his current research Professor Miyabe is trying to improve the predictability of the performance of packed wire screens in the regenerator. The parameters varied are 1) the diameter of the wire--50, 100, and 200 mesh, 2) the number of screens--approximately 200 to 400 , and 3) the length of the regenerator. Professor Miyabe does not go to the extent of studying flow or temperature distributions across the back of the screens. However, he uses a simplistic Stirling engine as a test rig rather than an oscillating flow test drive. He has also been making incremental improvements such as using backto-back, spring-loaded rod seals instead of simple seals in this engine.

Professor Miyabe has also studied the performance of foamed metal regenerators, manufactured by Sumitomo Electric Ltd. He noted that flow resistance was lower than the case of wire screens and that heat transfer was higher. However, the low density of currently available foamed metals adds an unacceptable amount of dead space. If manufacturers will produce more densely packed foamed metals, he feels this material will have significant promise for use in regenerators. He is not currently experimenting with this mater idl.

\subsubsection{Professor Takahashi}

At Meiji University, Professor Takahashi specializes in the analysis and simulation of fluid flow, particularly as it applies to Stirling engines. Professor Takahashi has constructed an experimental device to study oscillating flow in a regenerator. The device is composed of opposed pistons that are connected by a pipe of about 3 meters in length. No results are available but general flow characteristics, flow resistance and pressure drop are being investigated. Professor Takahashi is also planning simulations of his 
oscillating flow device. At the time of the interviews, the device was only 75\% complete but should have been finished early in 1987.

\subsubsection{Professor Nishimoto}

At Kanazawa University, Professor Nishimoto's early work focused on characterizing different regenerator materials. It began with some initial performance analysis in the early 1980's, focusing on regenerator efficiency and engine performance. He subsequently published a more detailed description of the regenerator work, which is summarized below, and he is currently involved in flil cycle testing with his test engine.

In 1985, four regenerator designs were tested: 1) $3 \mathrm{~mm}$ stainless steel balls, 2) $5 \mathrm{~mm}$ stainless steel balls, 3) 60 Mesh stainless steel wire-gauze, and 4) $15 \mathrm{~mm}$ diameter perforated copper ring. Performance characteristics that were measured included 1) the temperature difference, 2) the temperature rise versus the flow rate, 3) the pressure drop versus the flow rate, and 4) frictional, indicated and net work. The cooper ring offered the best performance in his tests, but there was experimental problems with the sealing and temperature performance, and endurance tests were needed.

\subsection{OSCILLATING FLOW RESEARCH}

In addition to oscillating flow testing of regenerators, two researchers are pursuing related examinations of such flows. Their work is outlined here.

\subsubsection{Dr. Hirata}

Dr. Hirata's oscillating flow research at the University of Tokyo is directed at a fundamental study of how the structure of the turbulent boundary layer changes in the presence of oscillating flow. He noted that william Reynolds is doing similar work at Stanford University and that this work was not limited to Stirling engines but is a fundamental study. In this way it differs from Professor Yoshiki's study of oscillating flow (outlined in the next section), which attempts to model full oscillation in a simulated heater head tube. 
In Dr. Hirata's work, the oscillation is induced by a butterfly valve located downstream of the heater. The amplitude of the oscillation is about one-half that of the main flow. A long pipe is used before the heater to allow fully developed turbulent flow. Hot wire anemometer measurements are taken just downstream of the heater. This research is being conducted by one of the Ph.D. students, Mr. Isshiki, for his dissertation. Mr. Isshiki is the son of Professor Isshiki, who was also interviewed in this project.

\subsubsection{Professor Yoshiki}

To analyze oscillating flow at the Institute of Industrial science, Professor Yoshiki has developed a large, experimental device to simulate the oscillating flow of the working gas in one Stirling heater head tube. The lab equipment consists of a long, U-shaped tube, 4 meters long on one side with a piston at the two terminal ends of the tube. Of the several oscillating flow set-ups in the universities and national laboratories, such as the Universities of Tokyo and Meiji, his apparatus most closely resembles a full cycle in a Stirling engine heater head tube. A schematic is shown in Figure 3.1 .

Professor Yoshiki's first series of experiments focused on analyzing flow characteristics such as velocity distributions in the pipe and the extent of turbulence. He has also examined bulk flow speed through experimentation and through numerical analysis.

Professor Yoshiki has recently begun research of the heat transfer characteristics of oscillating flow in his heater tube rig. He has placed a heater around one section of the tube and will be taking hot wire anemometer measurements at a point downstream of the heater.

\subsection{LITERATURE COMPARISON}

Results of the literature comparisons are presented below by university or professor. 


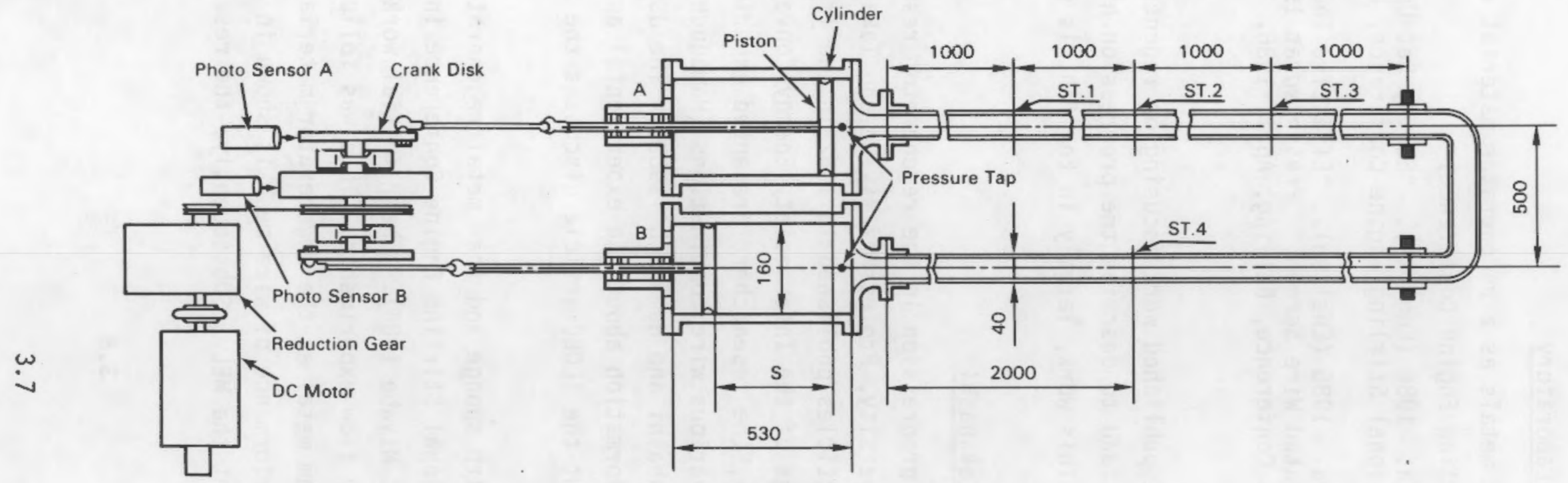

FIGURE 3.1. Schematic of the Laboratory Device Used by Professor Yoshiki for Oscillating Flow Experiments (scale in $\mathrm{mm}$ ) (Yoshiki et al. 1986) 


\subsubsection{Mechanical Engineering Laboratory}

At the MEL, tests on foam metals as a regenerator material were reported in the last International Stirling Engine Conference.

- Tanaka, M., and F. Chisaka. 1986 (English). "Easily Set-Up Regenerator." Presented at 3rd International Stirling Engine Conference, Rome, Italy.

- Tanaka, M., and F. Chisaka. 1986 (English). "Effective Thermal Conductivity of the Laminated Wire Screen." Presented at 1st Asian Thermophysical Properties Conference, Beijing, April 1986.

\subsubsection{Professor Isshiki}

Professor Isshiki has not published work focusing on regenerators or oscillating flow; he tends instead to describe the progress on his various engine development projects. This work, largely in English, is not listed here.

\subsubsection{Professors Miyabe and Takahashi}

The literature shows the progression in the regenerator research of the two Professors from Meiji University, Professors Miyabe and Takahashi, who often co-author papers. In articles published in 1982 in the Transactions of the JSME and the proceedings of the Intersociety Energy Conversion Engineering Conference (IECEC), the researchers presented experiments on the heat transfer performance of various wire combinations (Hamaguchi, Takahashi and Miyabe 1982a; Miyabe, Takahashi and Hamaguchi 1982). The JSME article, in Japanese, contains more information about the experimental apparatus and the results that were obtained, but the IECEC article discusses the essence of the work.

Results of experiments with sponge and foam metal regenerators were published at the 2nd International Stirling Engine Conference in Shanghai in 1984 (Takahashi, Hamaguchi and Miyabe 1984). Their initial work consisted of theoretical studies and steady flow experiments. This was followed by some experiments with sponge or foam metal as the regenerator material. An example of the comparison with the performance of wire mesh is shown in Figure 3.2; this work has been continued at the MEL. Subsequently, the researchers 


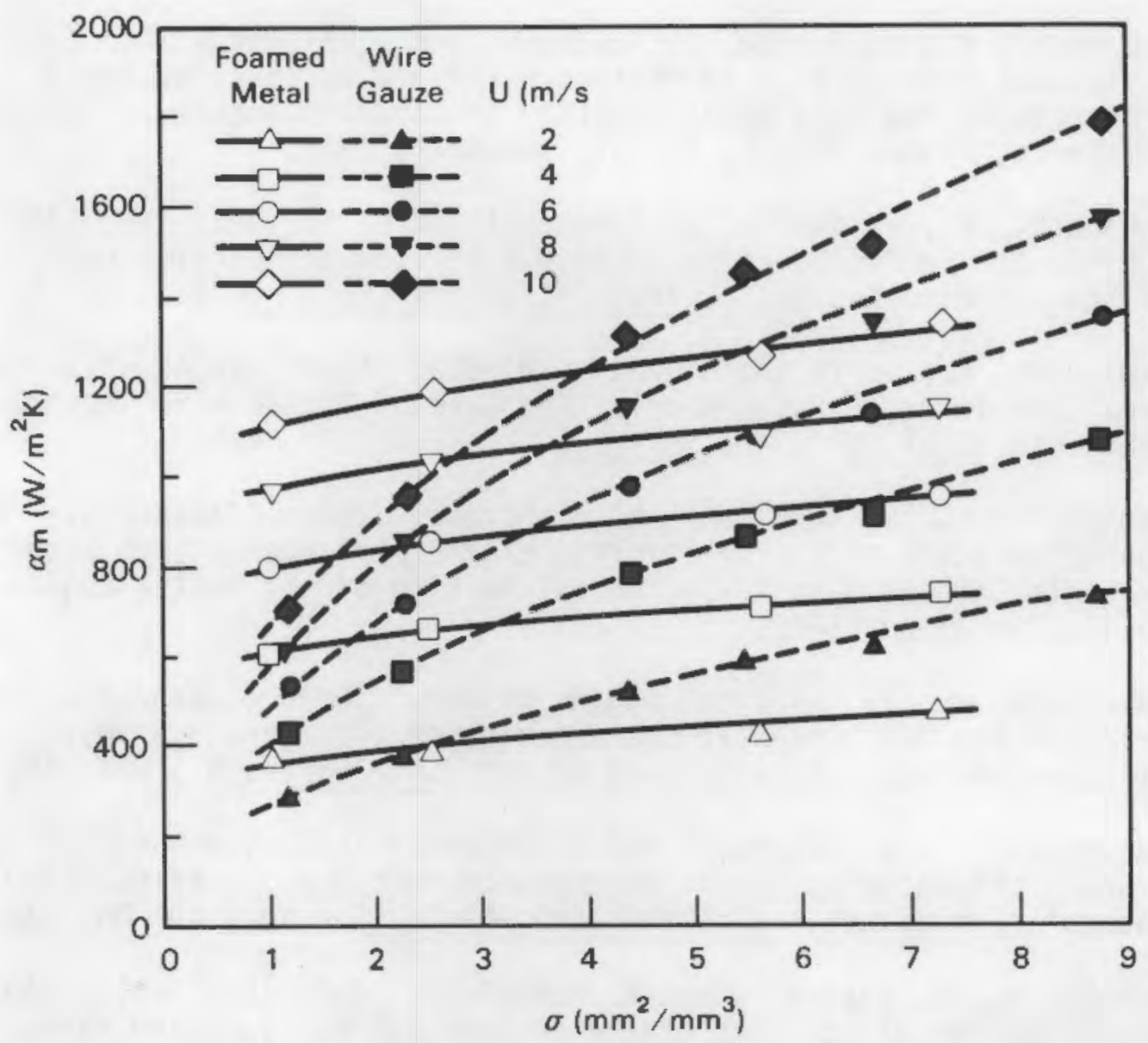

FIGURE 3.2. Comparison of Mean Heat Transfer Coefficients Between Wire Gauzes and Foamed Metals (Takahashi, Hamaguchi and Miyabe 1984)

initiated studies of the performance of wire mesh regenerators in the cyclic flow of the operating engine; this research is currently under way.

Miyabe and Takahashi tend to publish more frequently in Japanese, but the English articles that are available are representative of the various stages of their work. The Japanese articles, typically appearing in the Transactions of the JSME, are more detailed and more timely.

- Hamaguchi, K. 1982 (Japanese). "On the Choice Procedure of Optimum Matrix in Regenerator Design (Case of Stacked Wire Gauzes)." Iransactions of the JSME, Series B. Vol. 52, No. 473. 
- Hamaguchi, K., H. Kukita, S. Takahashi and H. Miyabe. 1985 (Japanese). "Selection Procedure of an Optimum Matrix in Regenerator Design." Presented at the 1985 Sendai Meeting of Japanese Society of Mechanical Engineers, Tohoku Branch, Sendai, November, 1985.

- Hamaguchi, K., H. Kukita, S. Takahashi and H. Miyabe. 1986 (Japanese). "On the Choice Procedure of Optimum Matrix in Regenerator Design (Case of Stacked Wire Gauzes)." Transactions of the JSME. Vol. 52, No. 473.

- Hamaguchi, K., S. Takahashi and H. Miyabe. 1982a (Japanese). "Pressure Drop Loss in Regenerator Matrix (The Case of Packed Wire Gauzes)." Iransactions of the JSME, Series B. Vol. 48, No. 435.

- Hamaguchi, K., S. Takahashi and H. Miyabe. 1982b (Japanese). "Regenerator Characteristics Affecting Stirling Engine Performance (3rd Report)." Presented at the 31st Spring Annual Meeting of the Marine Engineering Society in Japan, 1982.

- Hamaguchi, K., S. Takahashi and H. Miyabe. 1983a (Japanese). "Flow Friction and Heat Transfer Characteristics of Regenerator Matrix (Case of Foamed Metal). Transactions of the JSME, Series B. Vol. 49, No 445.

- Hamaguchi, K., S. Takahashi and H. Miyabe. 1983b (Japanese). "Heat Transfer Characteristics of Regenerator Matrix (Case of Packed Wire Gauzes)." Transactions of the JSME, Series B. Vol. 49, No. 445.

- Miyabe, H., S. Takahashi and K. Hamaguchi. 1982 (English). "An Approach to the Design of Stirling Engine Regenerator Matrix Using Packs of Wire Gauzes." Presented at the 17th Intersociety Energy Conversion Engineering Conference, Los Angeles, 1982.

- Takahashi, S., K. Hamaguchi and H. Miyabe. 1984 (English). "On the Flow Friction and Heat Transfer of the Foamed Metal as the Regenerator Matrix." Presented at the 2nd International Conference on Stirling Engines, Shanghai, 1984.

- Takahashi, S., K. Hamaguchi, H. Suzuki and H. Miyabe. 1982 (Japanese). "Regenerator Characteristics Affecting Stirling Engine Performance (3rd Report)." Presented at the 31st Spring Annual Meeting of the Marine Engineering Society in Japan, 1982.

\subsubsection{Dr. Hirata}

At the time of the interviews, Dr. Hirata's oscillating flow work had not been published. 


\subsubsection{Professor Yoshiki}

Professor Yoshiki's oscillating flow work has only recently appeared in the literature and is not yet available in English. The first paper describes experiments in measuring the velocity distribution in a circular tube with a hot wire. His second article describes theoretical predictions and experimental measurement of bulk flow. In 1986, he was setting up to conduct measurements of the heat transfer coefficients in oscillating flow.

- Yoshiki, H., S. Tsumura, Y. Endo and N. Takama. 1986 (Japanese). "A Study on Some Periodically Oscillating Flows in a Circular Pipe (Experi-mental Velocity Distributions)." Transactions of the JSME, Series B.

- Yoshiki, H., S. Tsumura, W. Toshihiki and N. Takama. 1986 (Japanese). "A Prediction of Stirling Engine Performance (1st Report), A Simple Method." Transactions of the JSME, Series B.

\subsubsection{Other}

Professor Nakajima at the University of Tokyo has been involved primarily with novel research but has published one article dealing with oscillating flow:

- Nakajima, N., N. Miyashita and M. Hirata. September 1980 (English). "The Characteristics of Pulsating Flow Heat Transfer in Stirling Engine." In Bulletin of the JSME. Vol. 8 , No. 3 .

At Kanazawa University, Professor Nishimoto's early work focused on characterizing different regenerator materials. It began with some initial performance analysis in the early 1980's, focusing on regenerator efficiency and engine performance. He subsequently published a more detailed description of his regenerator work, which is summarized below.

- Nishimoto, K., and S. Naka (Japan National Railway). 1982 (Japanese). "Study on Performance Analysis of Stirling Engine (1st Report, Regenerator Efficiency and Engine Performance)." Transactions of the JSME, Series B. Vol. 48 , No. 434 . 


\subsection{SEAL DEVELOPMENT}

Seal development is being investigated at the Mechanical Engineering Laboratory and by Professor Isshiki at his various working locations. Each is discussed in the following sections. The final section provides the literature comparison.

\subsection{MECHANICAL ENGINEERING LABORATORY}

Seal research takes place in two separate sections within the MEL. Research on the seal mechanism occurs in the Energy Conversion Division, and research on seal materials occurs in the Tribology Division. Approximately four researchers are involved in the overall effort. Dr. Yamashita, who coodinates most of the lab's Stirling engine research, noted that the two divisions will be cooperating more closely in the future.

In the Energy Conversion Division the researchers have developed a piston seal testing rig with a transparent cylinder. The researchers are focusing on analyzing the rib-type seal but are also looking at alternatives, such as the lip-type endless seals and seals with back-up rings. Rod seals are tested on a separate testing device. In the Tribology Division the researchers primarily have been experimenting with PTFE materials combined with additives such as carbon fibers or oil.

The research on the mechanical performance of seals at the MEL can be divided into roughly three phases of research. The initial work is represented by papers published in 1981 and 1982, which primarily describe the development and initial use of the seal testing apparatus (Tanaka 1981; Tanaka and Yamashita 1982). The second phase involved experiments with different shapes and types of seal materials with different working gases, and the third period involved research into the effect of the roughness of the surfaces. Because the first phase involved very preliminary work, it will not be discussed further. However, the publications from other phases will be briefly summarized below.

During the second phase, experiments with several forms of seal designs were conducted. Soon after, experiments were conducted using various seal 
materials: 1) PTFE, 2) PTFE with $15 \%$ weight carbon fibers, 3) PTFE with $15 \%$ weight copper dust, and 4) PTFE with carbon fibers and copper dust. Friction coefficients and wear rates were measured for these options using various gases: helium, nitrogen, hydrogen, dry air, and wet air. The surface structure was observed with an electron microscope. The combination of PTFE and carbon fibers was determined to have the most promising characteristics.

At about this time, the third phase began, with an interest in the effects of the surface roughness on the leakage rate. In 1984 static tests were performed. The effect of roughness on the performance of the PTFE and carbon fiber seal was reported later that year (Tanaka 1984). Sample test results are shown in Figures 4.1 and 4.2. Finally, in 1985 results of dynamic tests were reported with the PTFE and carbon fiber seal material (Tanaka and Yamashita 1985). A schematic of the experimental device is shown in Figure 4.3 and some results are shown in Figures 4.4 and 4.5 .

\subsection{PROFESSOR ISSHIKI}

The four engines that Professor Isshiki has worked on were described in Chapter 3.0: a $2 \mathrm{~kW}$ Stirling engine, an engine based on existing Sanden wobble-plate drive technology, a T-type Stirling engine, and a $200 \mathrm{hp} \mathrm{marine}$ stirling engine. The seal developments involved in those efforts are discussed below.

Professor Isshiki's effort to develop a $2 \mathrm{~kW}$ Stirling engine, which Tokyo Sanyo intends for the home heat pump and air conditioning market, has encountered a problem with the piston sealing. To address the problem, Professor Isshiki has patented a three-ring seal in Japan (he has not applied for a patent in the U.S.). The seal uses three 0-rings. The outer two rings serve as gas seals for the center ring, and only this center ring is designed to contact the cylinder wall, thereby minimizing the friction induced by the seal. This seal may also be used with the Sanden engine, as described below.

Professor Isshiki's staff at Nihon University is conducting research in support of Sanden's efforts to develop a small $2 \mathrm{~kW}$ Stirling engine based on 

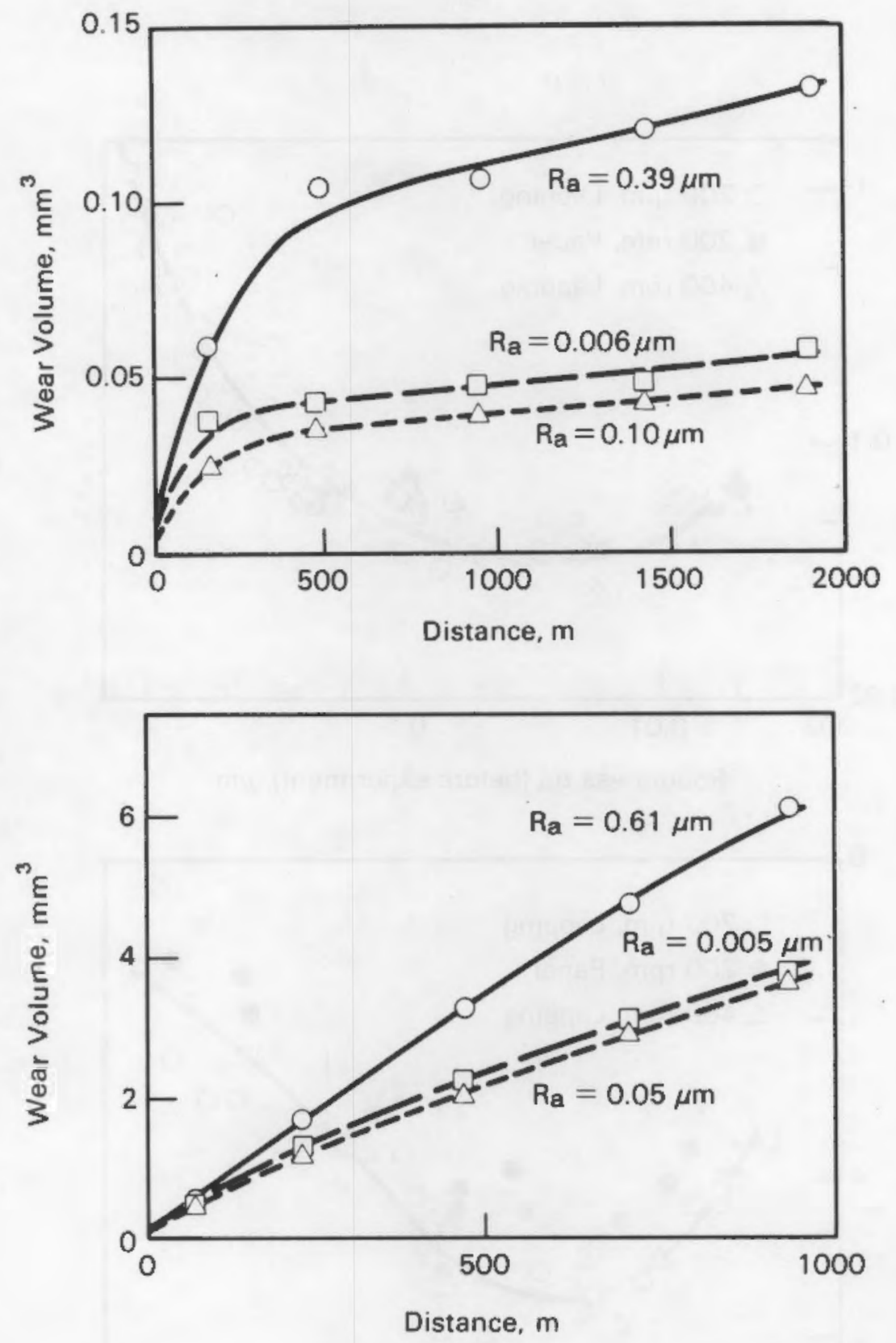

Specimen

Gas

Pressure

Normal Load

Speed

Roughness $\mathrm{Ra}$

Ring PTFE + 15\% Carbon Filter

Disk S55C (Hv-950)

$\mathrm{He}$

$0.9-1.2 \mathrm{MPa}$

220-700 N

210-900 rpm

Disk $0.008-0.85 \mathrm{~m}$

(before experiments)

Ring $0.6-0.7 \mu \mathrm{m}$

FIGURE 4.1. Relation Between Wear Loss and Coefficient of Friction with the Distance of Contact (Tanaka 1984) 


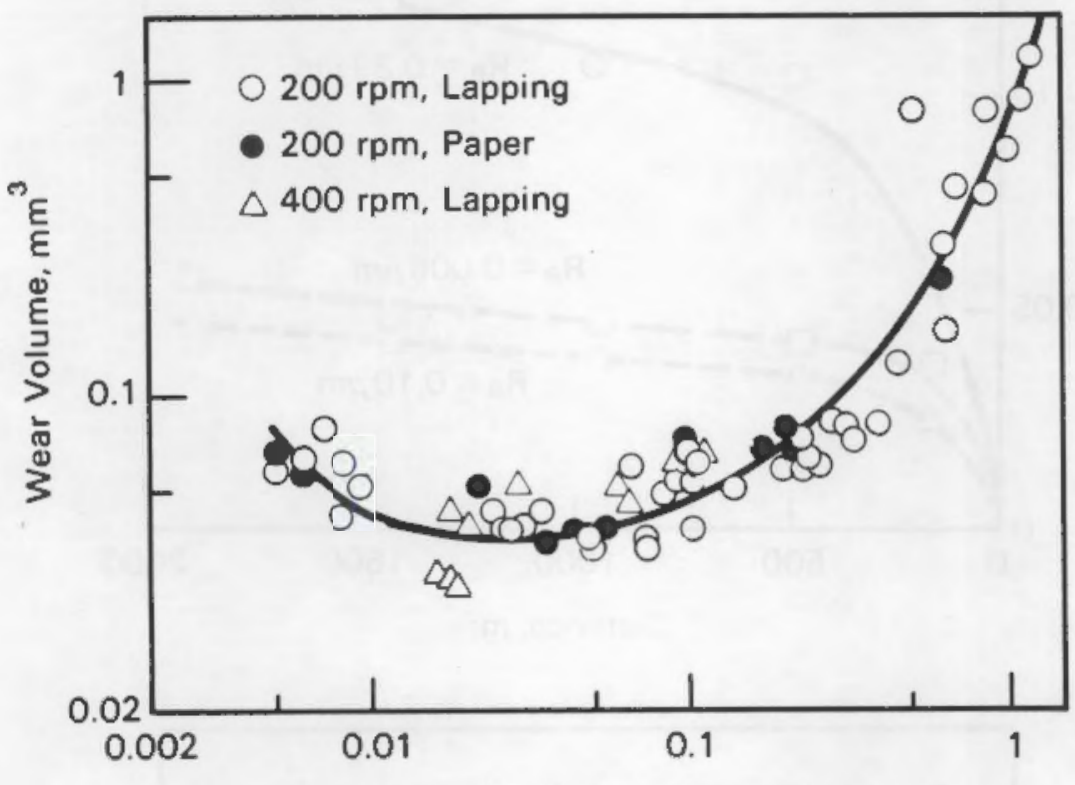

Roughness $\mathrm{R}_{\mathrm{a}}$ (before experiment), $\mu \mathrm{m}$

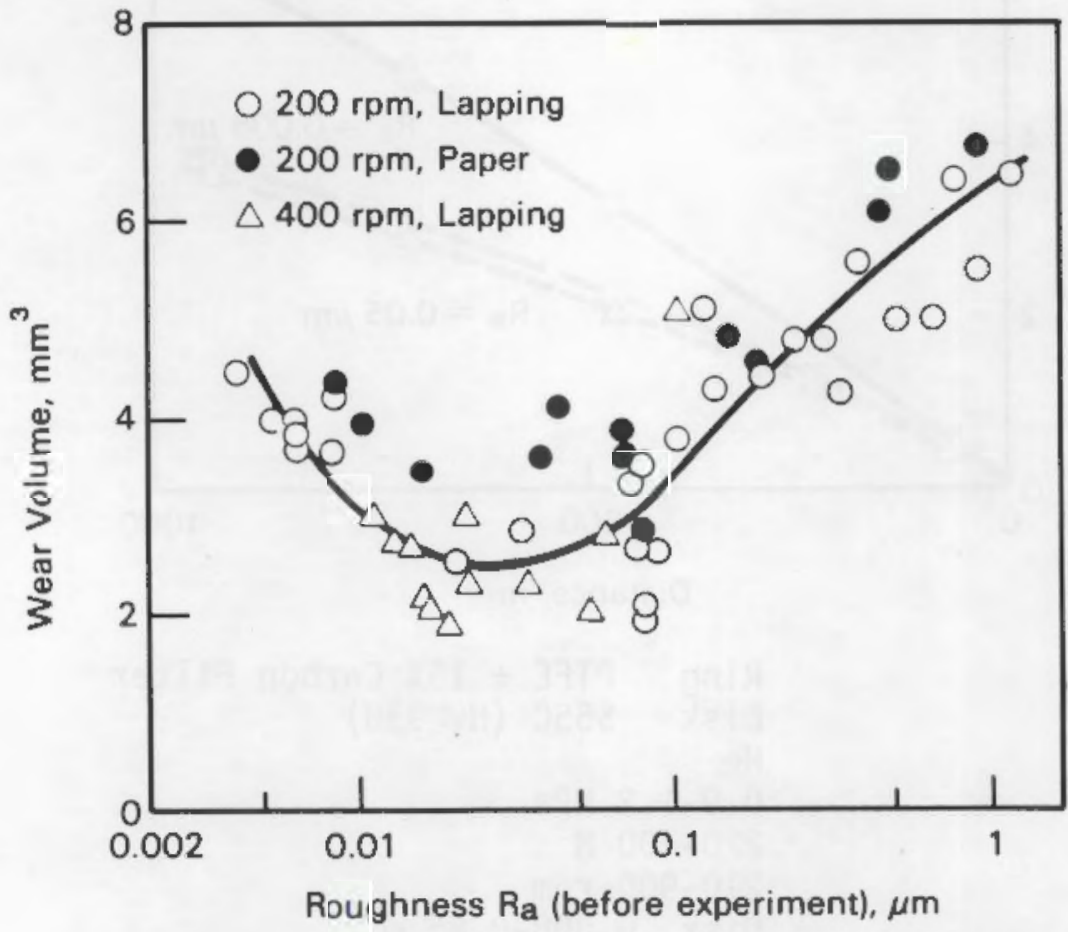

FIGURE 4.2. Relation Between Wear Loss and Surface Roughness (Tanaka 1984) 


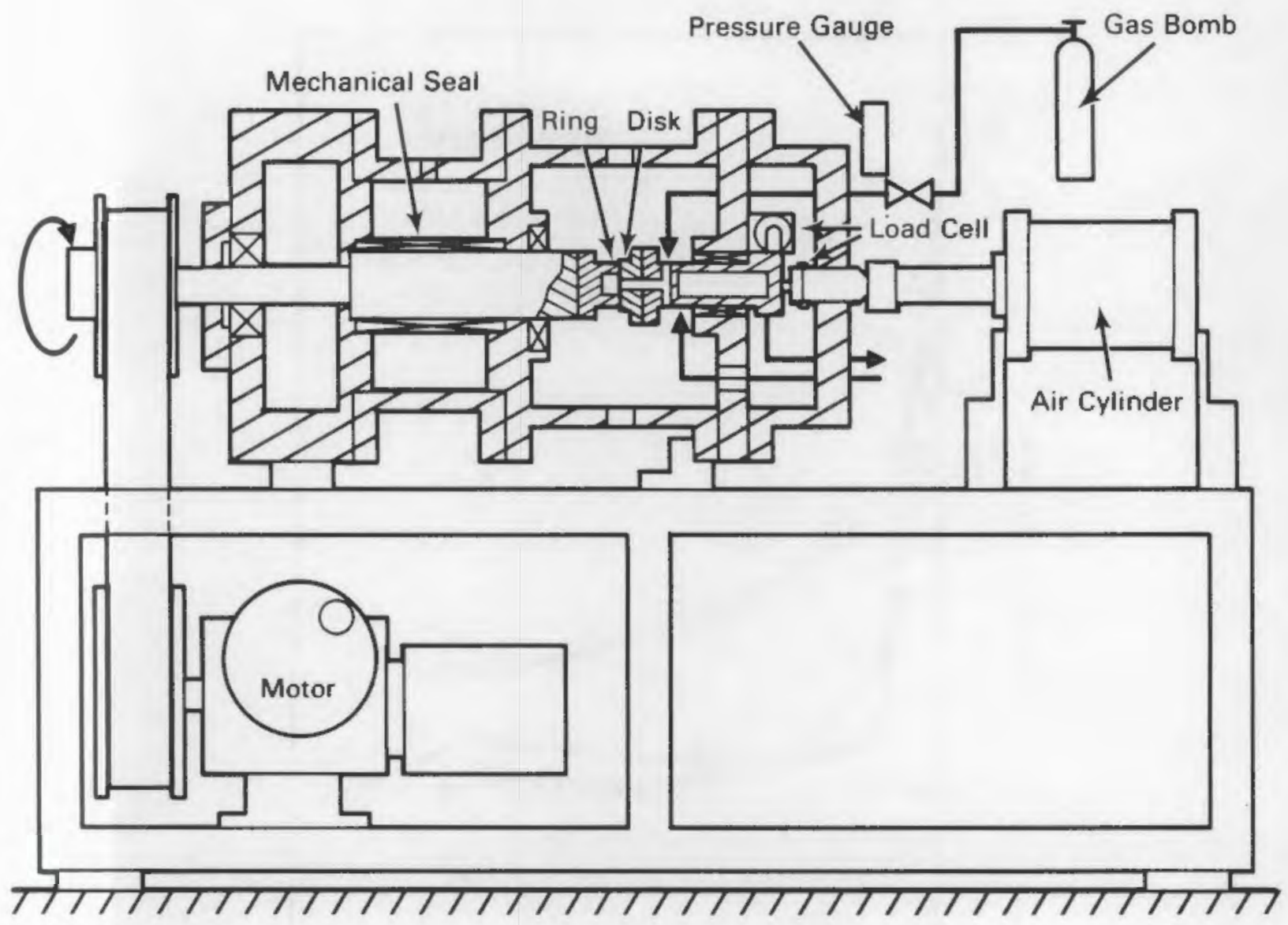

FIGURE 4.3. Schematic of Seal Testing Apparatus (Tanaka and Yamashita 1985) existing Sanden wobble-plate technology. Professor Isshiki is having a series of problems with the engine, one being leakage around the piston rings. This leakage problem is one of the projects being investigated at Nihon University. One of the seals being tested is Professor Isshiki's patented C-ring system.

At the Ship Research Institute, Professor Isshiki was involved in a Marine Stirling Project that involved development of a T-type Stirling engine and a $200 \mathrm{hp} \mathrm{marine} \mathrm{Stirling} \mathrm{engine} \mathrm{with} \mathrm{a} 155 \mathrm{~cm}$ diameter piston. The $200 \mathrm{hp} \mathrm{marine}$ Stirling engine appears to have largely ended in failure. Among the problems was large friction in the rod seals. However, the T-type engine is being used for general research. The equipment being used at the Institute for current research includes a rod seal tester and a piston seal tester. The 


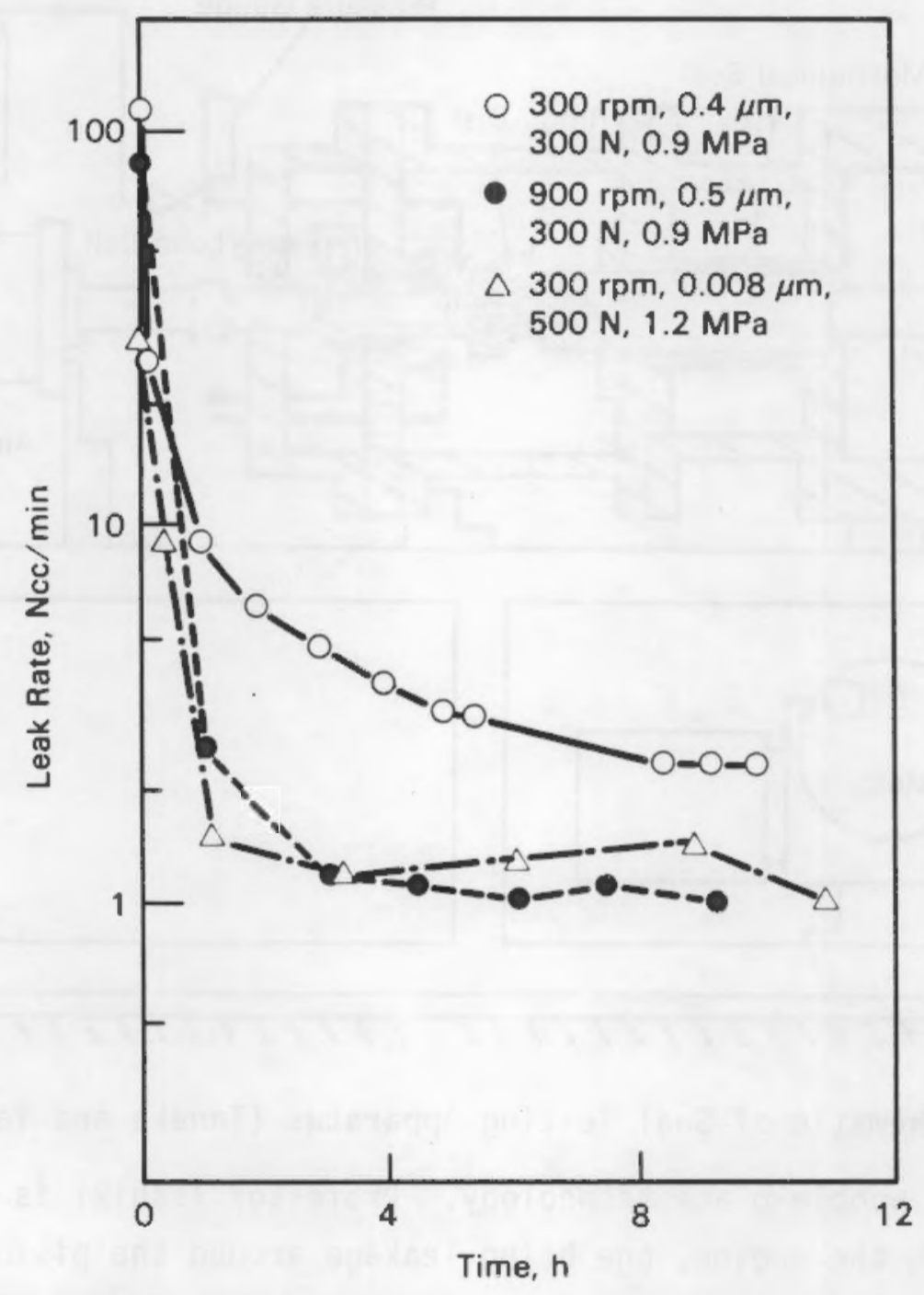

FIGURE 4.4. Relation Between Leakage Rate and Time (Tanaka and Yamashita 1985)

seal testers are conventional and used for measuring overall performance rather than for investigating the leakage and wear mechanisms.

\subsection{LITERATURE COMPARISON}

Only one article discussing Stirling engine seal research was published in English. The remainder discuss data from MEL's seal program in considerable detail. 


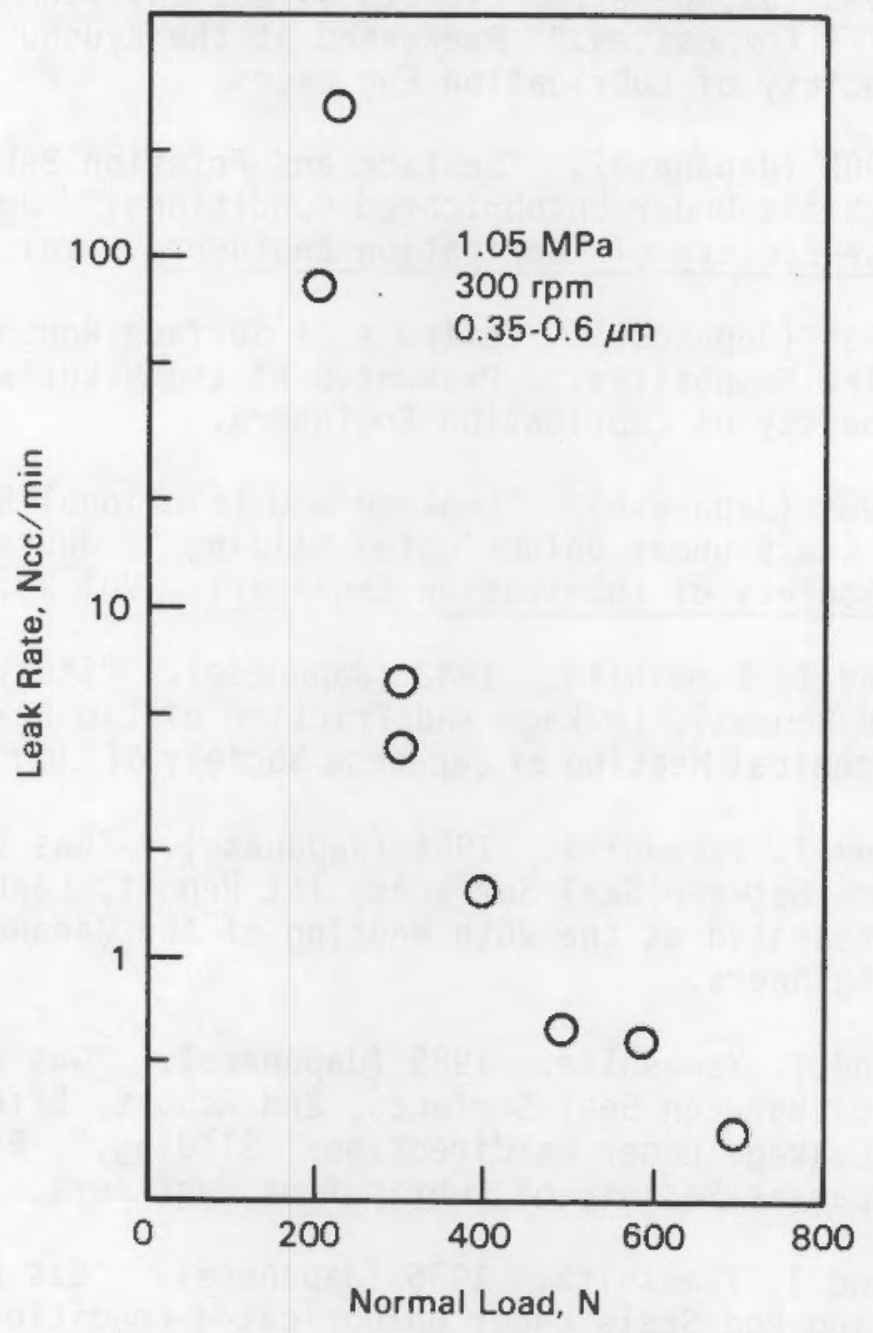

FIGURE 4.5. Relation Between Leakage Rate and Normal Load (Tanaka and Yamashita 1985)

- Mizuhara, K. 1986 (Japanese). "Effects of 0ils on Gas Permeability of Seal Materials." Presented at the 30th Technical Meeting of Japanese Society of Lubrication Engineers.

- Mizuhara, K., and Y. Tsuya. 1984 (Japanese). "Investigation of Seal Materials Selection for Stirling Engine." Presented at the 28th Technical Meeting of Japanese Society of Lubrication Engineers.

- Tanaka, A. 1981 (Japanese). "Study of Reciprocating Gas Seals (1st Report), Apparatus and Experiments." Presented at the 25th Technical Meeting of the Japanese Society of Lubrication Engineers. 
- Tanaka, A. 1983 (Japanese). "Effects of Gas Environments on Friction and Wear of PTFE Composites." Presented at the Kyushu Technical Meeting of Japanese Society of Lubrication Engineers.

- Tanaka, A. 1983 (Japanese). "Leakage and Friction Behavior of Reciprocating Seals Under Unlubricated Conditions." Junksatu, Journal of the Japanese Society of Lubrication Engineers. Vol. 29, No. 5.

- Tanaka, A. 1984 (Japanese). "Effects of Surface Roughness on Friction and Wear of PTFE Composites." Presented at the Hokuriku Technical Meeting of Japanese Society of Lubrication Engineers.

- Tanaka, A. 1984 (Japanese). "Leakage and Frictional Behaviors of Reciprocating Seals under Unlubricated Sliding." Junkatsu, Journal of the Japanese Society of Lubrication Engineers. Vol 29, No. 5.

- Tanaka, A., and I. Yamashita. 1982 (Japanese). "Study of Reciprocating Gas Seals (2nd Report), Leakage and Friction of Lip Seals." Presented at the 26th Technical Meeting of Japanese Society of Lubrication Engineers.

- Tanaka, A., and I. Yamashita. 1984 (Japanese). "Gas Leakage Characteristics Between Seal Surfaces, 1st Report, Leakage Between Static Surfaces." Presented at the 28th Meeting of the Japanese Society of Lubrication Engineers.

- Tanaka, A., and I. Yamashita. 1985 (Japanese). "Gas Leakage Characteristics Between Seal Surfaces, 2nd Report, Effect of Sliding Condition on Leakage under Unidirectional Sliding." Presented at Akita Meeting of Japanese Society of Lubrication Engineers.

- Tanaka, A., and I. Yamashita. 1986 (Japanese). "Gas Leakage and Friction of Reciprocating Rod Seals Under Unlubricated Condition." Journal of Japanese Society of Lubrication Engineers. Vol. 31, No. 12 .

- Watanabe, M. 1985 (Japanese). "Friction and Wear of PTFE Composites in He Gas." Presented at the 30th Technical Meeting of Japanese Society of Lubrication Engineers.

- Watanabe, M., and H. Yamaguchi. 1986 (English). "The Friction and Wear Properties of Nylon." Wear. No. 110.

Despite his activities in seal research, Professor Isshiki apparently has not published any papers on the subject other than material contained in his engine development programs (Chapter 8.0). 


\subsection{COMBUSTION RESEARCH}

Combustion research is being conducted at the National Aerospace Laboratory, at the Mechanical Engineering Laboratory, and by Professor Isshiki. The research of each is discussed in the sections below, followed by the literature comparison.

\subsection{NATIONAL AEROSPACE LABORATORY}

The principal role of the NAL in the Stirling Engine Heat Pump Project is to conduct supporting combustion research. The objectives of this effort are to provide design data on the high-intensity, low emission combustor for Stirling engines and to develop assessment technology for combustion performance and exhaust emissions. The Stirling-engine-related combustion research is divided into three categories: 1) burner development, 2) laser diagnostics, and 3) numerical simulation. This work is performed by seven laboratory researchers and four students and is funded by MITI through the Stirling Engines for Wide Use Project. When the project ends, they will have to revert to a lower level of funding provided by the laboratory. Below, the research in each category is discussed.

The research on the burner system includes investigation of flame shortening, homogeneous temperature profiles, and the general effects of swirl on combustion. This effort is staffed by two researchers and two students.

To investigate these basic combustion processes, NAL researchers are using laser doppler velocimetry (LDV) and coherent antistokes Raman spectroscopy (CARS). They have developed a portable CARS facility that can be moved to the burner test rig. One of the researchers in particular, Dr. Gomi, has been able to successfully manipulate CARS to maximize the information available from a single reading. They are measuring both temperature and exhaust species (e.g. $\mathrm{CO}, \mathrm{O}_{2}, \mathrm{NO}_{\mathrm{X}}$, etc.) concentrations.

In their numerical simulation work, NAL researchers are attempting to predict reacting flows in the stirling engine combustor. At the 1986 International Conference on Computational Mechanics, Dr. Eguchi presented a 
paper describing the application of NALTAC (National Aerospace Laboratory Thermo-Aerodynamics Code), a two-dimensional, axisymmetric simulation code, to the modeling of isothermal and reacting swirl flows. This effort is staffed by three researchers.

\subsection{MECHANICAL ENGINEERING LABORATORY}

The MEL does not have an explicit charter to perform combustion work as does the NAL. However, one of the generic categories of research being conducted at MEL is heat exchanger performance. That research is further subdivided, and one area involves $\mathrm{NO}_{x}$ reduction. Currently, researchers are examining the use of ammonium injection into the exhaust stream to create $\mathrm{N}_{2}$, $\mathrm{O}_{2}$, and $\mathrm{H}_{2} \mathrm{O}$. The general technique is widely used in industrial boilers. Researchers at MEL are experimenting with variables such as infection timing and ammonia concentrations. Initial results indicate that high reaction rates occur at approximately $1000^{\circ} \mathrm{C}$, which matches well with the preheater and heater temperatures. No publications are avallable yet regarding this work.

\subsection{PROFESSOR ISSHIKI}

As mentioned in previous chapters, Professor Isshiki and his laboratory at Nihon University are responsible for helping to develop the seals, the regenerator, and the heater head for a Sanden engine based on existing Sanden wobble-plate technology. Among the series of problems they are having with the engine is in the heater head, where the flame was apparently missing mucn of the heat transfer surface. This required a change in design.

Professor Isshiki also mentioned that the Ship Research Institute was supplying some funds for research on combustion-controlled power control systems. Response of the engine would be achieved by varying the combustion rate. He feels, however, that pressure control is still a better option. 


\subsection{LITERATURE COMPARISON}

The only publications found in the literature review concerned the NAL. The NAL's list of recent publications of combustion research related to Stirling engines indicates that fundamental research and simulations have been actively pursued. The researchers have published extensively in both English and Japanese. Of the 21 articles listed below, 10 are in English. Sometimes the researchers publish first in Japanese and then in English, and sometimes they write the original article in English.

Aside from the timeliness, there do not seem to be major differences between the English and the Japanese language articles. The one exception may the series of articles on high intensity swirl burners. Five articles have been published in Japanese, but only one in English, in 1983. However, some papers have been submitted under an IEA agreement related to combustion. For example, in 1983 the NAL researchers submitted an article on high intensity swirl burners; in 1984, they submitted a description of the testing of their codes by the use of a Stirling engine swirl burner; and in 1985 they submitted an article on the development of their prediction code for Stirling combustion flows to the IEA group.

- Eguchi, K. 1983 (English). "On High Intensity Swirl Burners." Presented at the 5th International Energy Agency Task Meeting, Norway, August 1983.

- Eguchi, K. 1983 (Japanese). "Study on High Intensity Swirl Burners for Stirling Engines, Part 1." Presented at the 21st National Symposium on Combustion, December 1983.

- Eguchi, K. 1985 (Japanese). "Study on High Intensity Swirl Burners, Part 4." Presented at the 23rd National Symposium on Combustion. Hi roshima, 1985.

- Eguchi, K., et al. 1984 (English). "A Design Approach to Stirling Burners with Intense Combustion: Part 1, Fundamental Combustion Characteristics." Presented at the 2nd International Conference on Stirling Engines, Shanghai, July 1984.

- Eguchi, K., et al. 1984 (Japanese). "Study on High Intensity Swirl Burners for Stirling Engines, Part 2." Presented at the 62nd Japanese Society of Mechanical Engineers Annual Technical Meeting, No. 840-14, october 1984. 
- Eguchi, K., et al. 1984 (Japanese). "Study on High Intensity Swirl Burners for Stirling Engines, Part 3." Presented at the Japanese Society oaf Mechanical Engineers, Technical Meeting, No. 848-3, December 1984.

- Eguchi, K., et al. 1985 (English). "A Prediction Code for Stirling Combustion Flows." Presented at the 7th International Energy Agency Task Leaders Meeting, Tokyo, August 1985.

- Eguchi, K., et al. 1986 (Japanese). "Flame Characteristics and $\mathrm{NO}_{\mathrm{X}}$ Emissions in High Intensity Swirl Burners." Presented at the 14th National Meeting on Gas Turbine Engines, July 1986.

- Eguchi, K., et al. 1986 (Japanese). "Study on High Intensity Swirl Burners, Part 5." Presented at the 24th National Symposium on Combustion, November 1986.

- Eguchi, K., and S. Fujii. 1984 (English). "The Capability Test of Computer Codes by Use of a Stirling Engine Swirl Burner." Presented at the 6th International Energy Agency Task Leaders Meeting, California, August 1984.

- Eguchi, K., and S. Fujii. 1985 (Japanese). "A Basic Computer Code for Stirling Combustor Designs Progress Report, Part 1, High Efficiency and Low Emission Design Technology for Continuous Combustion Systems." Report of JSME RC 67 Committee, April 1985.

- Eguchi, K., and S. Fujii. 1984 (Japanese). "A Basic Computer Code for Stirling Burner Designs." Presented at the 2nd National Aerospace Laboratory Symposium on Aircraft Computational Aerodynamics, NAL SP-3, July 1984 .

- Eguchi, K., S. Fujil and Y. Sugiyama. 1986 (English). "Development of a Prediction Code for Stirling Combustion Flows." Presented at the International Conference on Computational Mechanics, Tokyo, May 1986.

- Gomi, M., et. al. 1986 (Japanese). "Application of Simplified CARS to Practical Burners." Presented at the 24 th National Symposium on Combustion, November 1986.

- Gomi, M., Y. Watanabe and S. Fujii. 1985 (English). "Improvements in CARS Measurement System for Practical Burners." Presented at the 7 th International Energy Agency Task Leaders Meeting, Tokyo, August 1985.

- Fujii, S. 1986 (Japanese). "A Simplified Temperature Measurement System by CARS." Presented at the 23rd National Symposium on Heat Transfer. Sapporo, 1986. 
- Fujii, S., et al. 1984 (English). "Practical Application Techniques of Coherent Anti-Stokes Raman Spectroscopy (CARS) to Remote-Detection Systems." Presented at the 9th International Conference on Raman Spectroscopy, Tokyo, 1984 .

- Fujii, S., and K.. Eguchi. 1983 (Japanese). "A Basic Code of Numerical Simulation for GT Combustor Designs." Presented at the 92nd Japanese Society of Mechanical Engineers Meeting of Thermal Engineering, November, 1983.

- Fujii, S., K. Eguchi and M. Gomi. 1983 (English). "Analysis and Laser Probe Measurement of Swirling and Bluff Body." ASME 83-GTJ-11, Presented at the 1983 Tokyo Joint Gas Turbine Congress, $19 \mathrm{~B} 3$.

- Fujii, S., and M. Gomi. 1984 (English). "The Refinement of CARS Temperature and Oxygen Measurement Techniques." Presented at the 6th International Energy Agency Task Leaders Meeting, California, August 1984.

- Fujii, S., M. Gomi and K. Eguchi, 1983 (English). "A Remote-Probe System for Velocity and Temperature Measurements." ASME Transactions, Journal of Fluid Engineering. Vol. 105. 


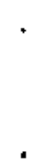

• .

( 


\subsection{SIMULATION RESEARCH}

Simulation work is being conducted at the Mechanical Engineering Laboratory and by Professors Nakajima and Yoshiki. Each is discussed below, followed by the literature comparison.

\subsection{MECHANICAL ENGINEERING LABORATORY}

Most of the simulation work at the MEL has focused on cycle simulation. Previously, Dr. Azetsu, who is now teaching at Tokyo University, developed a 50 space model of the engine.

Currently, two researchers are involved with the simulation work, developing a more simplified model that can be used more interactively with experiments. A simple approach is also desired because computer time is expensive. They noted that more data are now available for verifying a simplified model. Also, they are planning to develop a CAD (computer-aided design) model of a stirling engine.

A1l of this work has focused on kinematic (crank drive) Stirling engine design. Some numerical analysis of a free piston design was conducted in 1981-82, but this work was not continued.

\subsection{PROFESSOR NAKAJIMA}

At Tokyo University, Professor Nakajima worked with Professor Azetsu and Dr. Hirata on developing a five-space computer simulation of the Stirling engine. Dr. Azetsu later took this experience to MEL where he developed a 50-space computer code. This code is very expensive to run, however. Professor Nakajima is associated with a CAD lab at the university and hopes to apply CAD to Stirling engines.

\subsection{PROFESSOR YOSHIKI}

At the Institute of Industrial Science, Professor Yoshiki worked on Stirling engine cycle simulation. He focused on developing a five-space model, 
showing the importance of cooler space volume on the engine's efficiency. He completed the model's development in the early 1980's.

\subsection{LITERATURE COMPARISON}

Results of the literature comparison are presented below by laboratory and professor.

\subsubsection{Mechanical Engineering Laboratory}

The literature review and interviews did not reveal any publications on the multicell (50 space) model that was developed at the MEL a couple of years ago. Dr. Azetsu, who was in charge of that project, is now a professor at Tckyo University, but is spending little or no time on Stirling engine research. Staff at MEL currently are involved with developing more simplified models that can be used interactively with the experiments and with developing a $C_{A}[$ model of the engine.

- Yamashita, I., and Y. Hasegawa. 1982 (Japanese). "Numerical Analysis of a Free Piston Stirling Engine." Presented at the 57th Kansai Technical Meeting of the Japanese Society of Mechanical Engineers, 1982.

\subsubsection{Professor Nakajima}

At the University of Tokyo, Professor Nakajima worked on computer simulations of the Stirling engine in the early 1980's with Professors Hirata and Azetsu. Most of this work related to straightforward simulations and testing of the model with a laboratory engine. Review of the publication list shows that several of the articles were first published in Japanese and then translated directly into English.

- Azetsu, A. 1982 (Japanese). "The Analysis of Performance of Stirling Engines (1st Report, Computer Simulation Model)." Transactions of the JSME, Series B. Vol. 48, No. 428, 1982.

- Azetsu, A., N. Nakajima, and M. Hirata. 1982 (English). "Computer Simulation Model for Stirling Engine." I Mech E, C17/82, 1982.

- Nakajima, N., A. Azetsu and M. Hirata. 1981 (Japanese). "Experimental Evaluations of Stirling Engine Simulations." Journal of the Marine Engine Society in Japan. Vol. 16, No. 1 . 
- Nakajima, N., A. Azetsu and M. Hirata. March 1982 (English). "Experimental Evaluations of Stirling Engine Simulations." Bulletin of the JSME. Vol. 10. No. 1.

\subsubsection{Professor Yoshiki}

At the Institute of Industrial Science, Professor Yoshiki was involved with cycle simulations in the early 1980 's. This work has been well explained in an English article listed below, "A Prediction of Stirling Engine Performance."

- Yoshiki, H., H. Takama and M. Uemure. 1984 (English). "A Prediction of Stirling Engine Performance (1st Report) A Simple Method." Transactions of the JSME, Series B. Vol. 50, No. 455.

- Yoshiki, H., M. Uemura and N. Takama. 1980 (Japanese). "A Simple Method of Predicting the Stirling Engine Performance (2nd Report), Consideration of the Adiabatic Expansion Temperature." Seisan-Kenkyu Monthly Journal of the Institute of Industrial Science. Vol. 32, No. 9.

- Yoshiki, H., M. Uemura and N. Takama. 1980 (Japanese). "A Simple Method of Predicting the Stirling Engine Performance (3rd Report) Consideration of the Expansion and Compression Temperature." Seisan-Kenkyu Monthly Journal of the Institute of Industrial Science. Vol. 32, No. 10.

\section{4 .4 other}

Professor Isshiki is one of the most active Stirling engine researchers in Japan. Although simulation research is not one of his primary focuses, he has published a few relevant articles:

- Isshiki, N., and S. Tsukahara (Ship Research Institute). 1984 (English). "Approximate Estimations of Power and Various Losses of Stirling Engine." Presented at the 2nd International Conference on Stirling Engines, Shanghai, 1984 .

- Isshiki, N., S. Tsukahara and F. Terada (Tokyo Sanyo). 1984 (English). "Analysis of Various Internal Losses in Stirling Engines." Presented at the 19th Intersociety Energy Conversion Engineering Conference, 1984.

- Isshiki, N., H. Watanabe and A. Mitsuishi. 1986 (English). "Estimation of Losses in Stirling Engines." Presented at the 3rd International Stirling Engine Conference, 1986. 


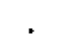

. 


\subsection{NOVEL RESEARCH}

Novel research is being conducted by several of the interview participants: staff at the MEL and Pollution and Natural Resources Laboratory, Dr. Hirata, Professor Nakajima, and Professor Fujii. The work by each is discussed below, followed by the literature comparison.

\subsection{MECHANICAL ENGINEERING LABORATORY}

Staff at the MEL are conducting heat exchanger research in three areas; one area involves novel research into developing a fluidized-bed heat exchanger for the heater head and augmenting heat transfer through radiation. The principal objective of Dr. Yamada, who heads the fluidized-bed research, is to measure the heat transfer coefficient of the fluid bed. He is using small aluminum-oxide $\left(\mathrm{Al}_{2} \mathrm{O}_{3}\right)$ pellets of less than $0.5 \mathrm{~mm}$ diameter as the bed. The pellets are placed over straight and finned heat transfer tubes. A schematic of the device and heat transfer measurements are included in Figure 7.1. Until recently, the experiments have been conducted using hot air to heat the fluidized bed. Now, however, they are experimenting with gas combustion in the fluidized bed.

A second method of performance improvement being pursued is heat transfer augmentation through radiation. The researchers are currently modeling the effect of improved wall radiation on heat transfer. They have experimented with radiation plates between the tubes and with wire mesh. The modeling experiments have all been performed under steady-state conditions.

\subsection{POLLUTION AND NATURAL RESOURCES LABORATORY}

Research at this laboratory focuses on the combustion characteristics of various solid biomass fuels. Compared with the MEL, research at this laboratory is at a much lower level of effort. Most of the research is conducted by Dr. Ohyanagi, and his focus is on the combustion of biomass and alternative fuels. He has been conducting this work for about two years. 

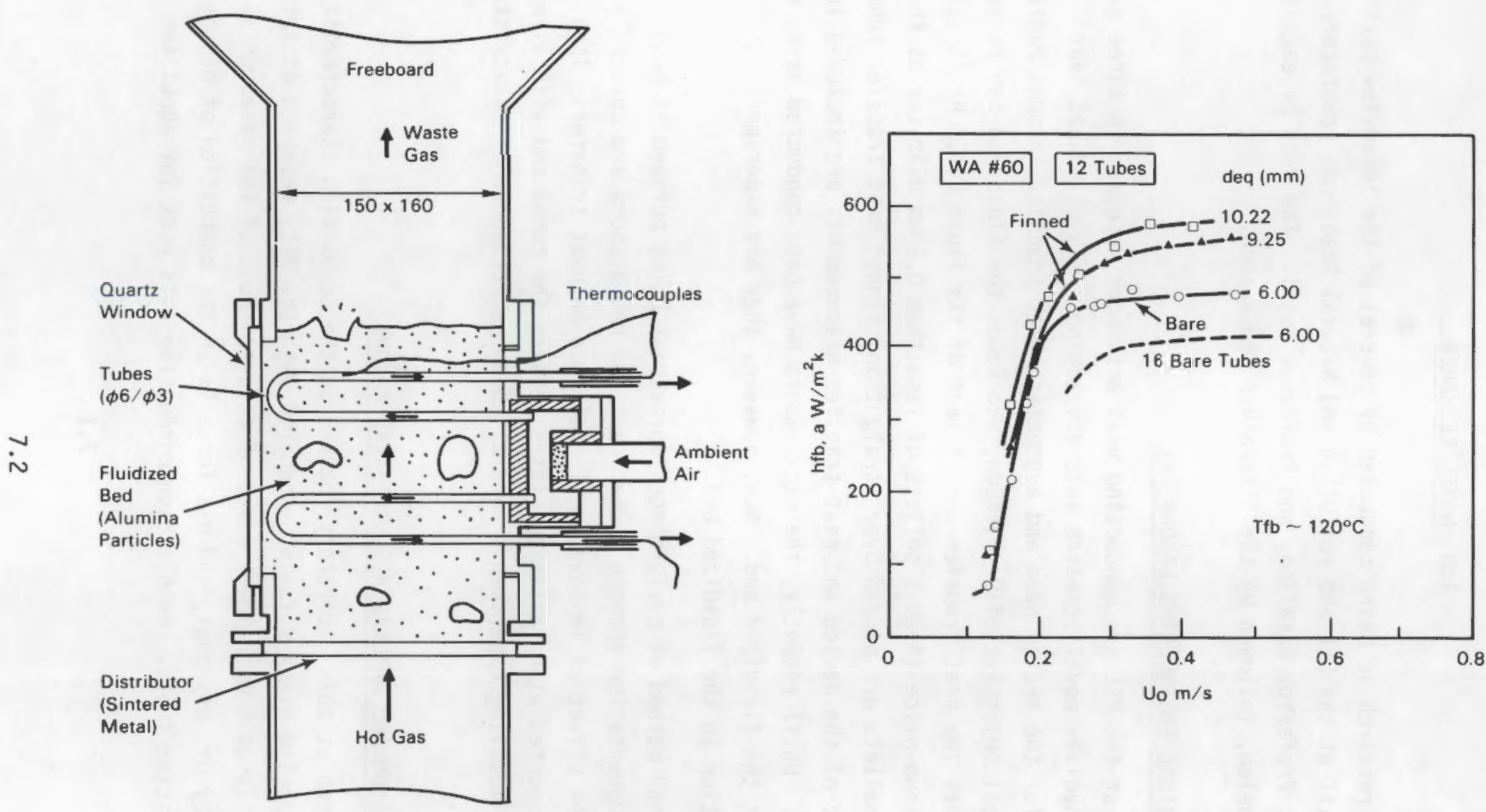

FIGURE 7.1. Schematic of the Fluidized Bed Heat Exchanger and Measurements of the Heat Transfer Coefficient (Yamada 1986) 
Dr. Ohyanagi noted that he has been concentrating on the study of biomass combustion characteristics, particularly ignition time and burning time. The principal fuel he is experimenting with is pelletized wood, al though he has burned a wide range of fuels from rice husks to garbage. He noted that wood generates a very small amount of waste (ash), about $1 \%$ to $2 \%$, in comparison with coal, $10 \%$ to $15 \%$. His laboratory consists of a biomass feeder, a combustion grating, a simulated Stirling heater head in the exhaust stream, and associated controls. The Stirling heater head is instrumented with thermocouples to indicate the temperatures that can be achieved. He noted that temperatures of $700^{\circ} \mathrm{C}$ to $800^{\circ} \mathrm{C}$ can be obtained by burning the bark waste from Japanese Cedar.

Dr. Ohyanagi noted that Aisin Seiki and Tokyo Sanyo have recently taken an interest in developing biomass systems for Stirling engines. Aisin Seiki is working on a gasified biomass system that they set up in March 1987. Tokyo Sanyo is investigating the combustion of alcohol (methanol) in a facility constructed in 1986.

\subsection{DR. HIRATA}

Staff at Tokyo University, led by Dr. Hirata, are investigating twophase, two-component working fluids because of the theoretically higher heat transfer coefficient that can be achieved from the evaporation and condensation processes. The actual improvements in net work are shown in Table 7.1. The research is focusing on thermodynamic and heat transfer characteristics of air-water mixtures, although air-freon mixtures have also been tested. Dr. Hirata noted that the performance of the heat exchange is heavily influenced by the mixture ratios. He further noted that the experimental performance of the two-component mixtures has to date been much lower than the predicted performance. He feels, however, that the principal problem is the operation of the test equipment, and they are making design changes to address those problems. 
TABLE 7.1. Single Phase Cycle and Two Phase Cycle

(Matsuno, Kasagi and Nirata 1986)

Net Work $(\mathrm{kJ} / \mathrm{kg})$ Therma] Efficiency

With Water

in Superheat

2-component,

125

0.172

2-phase

1-component

34.7

0.173

With R-113

in Superheat

2-component

0.687

0.186

2-phase

1-component

0.239

0.199

\subsection{PROFESSOR NAKAJIMA}

Currently, Professor Nakajima's research at Tokyo University centers on developing a fluidized bed for the heater head and on using biomass as the fuel. His initial experiments with fluidized-bed heat exchange have shown a more uniform distribution of heat over the heater head and a doubling of the heat transfer rate over conventional gas-firing methods. He has used computer analysis to help optimize and redesign the heater head. He also noted that his lab uses an ultrasonic temperature meter, which offers very fast response.

Research on a fluidized-bed, biomass-fired Stirling engine/generator was directed toward a $2 \mathrm{~kW}$ design that might be used for operating a greenhouse or for drying. They have achieved their electric and thermal efficiency goals (the latter was rather low at $10 \%$ ), but the rpm is still lower than desired. The goal is $2000 \mathrm{rpm}$ with air as the working fluid, but only $600 \mathrm{rpm}$ has been achieved (1200 rpm with helium). Professor Nakajima is planning a computer simulation of the system to address, in part, the flow friction causing the rpm problem. 
This work has been funded by a think tank called Technova, associated with Aisin Seiki, and by a semi-public organization called the Mechanical Social System Foundation. This later organization receives funding through MITI from taxes on motorcycle and bicycle racing. However, funding from both resources recently ceased, so Professor Nakajima was relying on university funds. He noted that future research is likely to focus on developing the fluidized-bed combustion system rather than the Stirling engine.

\subsection{PROFESSOR FUJII}

At Meiji University, Professor Fujii has several projects under way, one of which involves using solar energy for Stirling engines. He has a parabolic collector (about $5 \mathrm{~m}$ diameter) just outside his laboratory. A] though he performs occasional tests, this does not seem to be an area of high activity. His primary concern regarding Stirling engines seems to be the design of the head for Solar absorption.

\subsection{LITERATURE COMPARISON}

Results of the literature comparison are presented below for each lab and professor.

\subsubsection{Mechanical Engineering Laboratory}

At MEL the fluidized bed work is the main novel research activity. Articles are not available in English, although a translated version of the paper listed below was to be presented at the 1987 joint meeting of the American Society of Mechanical Engineers and Japanese Society of Mechanical Engineers.

- Yamada, Y. 1986 (Japanese). "Fundamental Study on Fluidized Bed Heat Exchangers for Stirling Engines." Presented at the 23rd National Symposium on Heat Transfer. May 1986, Sapporo.

\subsubsection{Pollution and Natural Resources Laboratory}

At the Pollution and Natural Resources Laboratory, the first article on the combustion of biomass and alternative fuels was published in 1986. 
- Ohyanagi, Y., and S. Masumoto. 1986 (Japanese). "Combustion Characteristics of Wood, Part 1, Ignition Time of Dried Wood." Bulletin of the National Research Institute for Pollution and Resources. No. 16.

\subsubsection{Dr. Hirata}

Several publications describing Dr. Hirata's two-phase flow work are available. Papers were presented in English at the Intersociety Energy Conversion Engineering Conference and at the Second International Stirling Engine Conference in Shanghai in 1984. Since then, Dr. Hirata and staff have published one more analysis article and an article describing initial tests with their laboratory rig.

- Akagawa, H., N. Kasagi and M. Hirata. 1983 (English). "A Study on an Air-Water Stirling Engine." Presented at the 18th Intersociety Energy Conversion Engineering Conference.

- Hirata, M., N. Kasagi and Y. Matsuno. 1984 (English). "8asic Cycle Analys is of Two-Component, Two-Phase Stirling Engine." Presented at the 2nd International Stirling Engine Conference, Shanghai, 1984.

- Iwasaki, E., and M. Hirata. 1982 (Japanese). "Study of a Two-Phase, Two-Component Stirling Engine." Iransactions of the JSME, Series B. Vol. 48 , No. 434 .

- Matsuno, Y., N. Kasagi and M. Hirata. 1986 (draft) (Japanese). "Thermodynamic Analysis of the Two-Component, Two-Phase Stirling Cycle." Transactions of the JSME, Series B.

\subsubsection{Professor Nakajima}

For the past couple of years, Professor Nakajima has been experimenting with coupling biomass combustion to a stirling engine. He noted that interest in this technology seemed to be greater in the international community than in Japan, so he has published much of his work in English.

- Nakajima, N. 1986 (English). "State-of-the-Art of the Stirling Engine - Japanese Experiences." Study Meeting on the Applications of A1ternative Energy Sources, February 1986.

- Nakajima, N., H. Kohno and A. Azetsu. 1985 (English). "Development of a Multi-Purpose Stirling Engine Driven by Wood Fuel." Presented at the 20th Intersociety Energy Conversion Engineering Conference, Miami Beach, 1985. 
- Nakajima, N., K. Tanimoto, A. Azetsu and Y. Mori (Nissan Motor Co). 1984 (English). "Study on Multi-Purpose Stirling Engines Designed to Burn Biomass." Presented at the 2nd International Stirling Engine Conference, Shanghai, 1984.

\subsubsection{Professor Fujii}

Professor Fugij has published one paper on his work on solar applications for Stirling engines.

- Fujii, I., K. Tsuchiya and I. Kaneda. 1984 (English). "On the Trial Investigation of Solar Hot Air Engine." Presented at the 2nd International Conference on Stirling Engines, Shanghai, 1984.

\subsubsection{Other}

Professor Isshiki has presented a paper on ceramic engines, although it is not an area in which he is particularly active..

- Takahashi, S. (Asahi Glass), Isshiki, N. and N. Oda. 1984 (English). "Study on Ceramic Stirling Engine." Presented at the 2nd International Conference on Stirling Engines, Shanghai. 
. 


\subsection{ENGINE DEVELOPMENT}

Research on engine development is being conducted at the Mechanical Engineering Laboratory and by Professors Isshiki and Nishimoto. The work of each is discussed below, followed by the literature comparison.

\subsection{MECHANICAL ENGINEERING LABORATORY}

At MEL one of primary stirling engine research activities involves comparison between simulation and tests. Three test engines have been developed at the MEL for component testing and verification of the computer models. These engines are the MELSE II (Mechanical Engineering Laboratory Stirling Engine II), MELSE III, and MELSE V.

The MELSE II is a simple two-chamber, U-shaped vertical design. This engine was designed for testing the main components, such as the heat exchangers and gas sealing device. The expansion and compression pistons have the same diameter $(8 \mathrm{~cm}$ ), the stroke is $6 \mathrm{~cm}$, and swept volume is 302 $\mathrm{cm}^{3}$. The maximum power generated by this engine is about $3.1 \mathrm{~kW}$ at a heater tube temperature of $700^{\circ} \mathrm{C}$, an engine speed of $1000 \mathrm{rpm}$, and a mean pressure of $4.5 \mathrm{MPa}$.

The next engine developed was the MELSE III, which is a three-cylinder, displacer-type, double-acting stirling engine. The engine has two displacers and one double-acting power piston. This engine was designed to allow double-acting piston experiments, electronic phase control testing, and additional component testing such as rod seal experiments. A maximum shaft power of $4 \mathrm{~kW}$ was obtained using helium as the working gas at a mean pressure of 4.7 MPa and an engine speed of $1000 \mathrm{rpm}$. These test results were reported at the Third International Stirling Engine Conference (Azetsu et al. 1986).

Recently, the configuration of the MELSE III has been changed to a single-acting design. One of the displacers was cut off to permit easier component testing and simulation. They noted that regenerator experiments are easier, electronic power control is more easjly implemented, and agreement with cycle simulations is more easily achieved. 
Most recently, the researchers at the MEL have developed the MELSE $V$ Stirling engine, which has a $V$-shaped design. The MELSE $V$ is designed such that hydrogen can be used as the working fluid and a fluidized bed can be used as the heater head. Experiments have begun with this engine but results have not been reported.

\subsection{PROFESSOR ISSHIKI}

Professor Isshiki's work for Tokyo Sanyo, Sanden, and the Ship Research Institute primarily centers around engine development. Each effort is discussed in the following subsections.

\subsubsection{Tokyo Sanyo}

As mentioned in other chapters, Professor Isshiki is working on developing a $2 \mathrm{~kW}$ Stirling engine which Tokyo Sanyo intends for the home heat pump and air conditioning market.

At Tokyo Sanyo's own laboratory, the Stirling engine staff is largely devoted to developing the $30 \mathrm{~kW}$ engine for the Moonlight Project. An administrative decision was made that the development of two Stirling engines was not to be pursued in the same lab. Staff from Tokyo Sanyo consult with Professor Isshiki on the development of the $2 \mathrm{~kW}$ Stirling engine but for the present, development seems to be largely left to him and the staff at the Ship Research Institute, who are spending about half of their time working on the Sanyo engine.

Professor Isshiki has been working on the Tokyo Sanyo $2 \mathrm{~kW}$ engine for several years. He feels that they have developed a simple and cost-effective design and the process is about two-thirds complete. The heater head uses a simple U-shaped design. Forming the head only requires simple milling and everything is soldered in one furnace. The material is stainless steel.

His current goal is to improve the efficiency of the engine, which is currently below $20 \%$, to $25 \%$. Although he is not on a strict schedule with the development of this engine, at the time of the interviews in 1986, he felt that he could achieve the $25 \%$ efficiency goal in about two years. One challenge was to make the engine tight: to minimize aspiration and maintain 
the pressure balance. As discussed in Chapter 4.0, Professor Isshiki addressed the piston sealing problem by patenting a three ring seal. This seal may also be used with the Sanden engine, as described in the next subsection. Professor Isshiki feels that the major problem with the $2 \mathrm{~kW}$ engine was improving the regenerator efficlency; this problem is discussed in more detail in Chapter 3.0. The engine has been tested up to a pressure to 45 bar and a temperature of $750^{\circ} \mathrm{C}$; tests up to $60 \mathrm{bar}$ and $800^{\circ} \mathrm{C}$ were planned.

\subsubsection{Sanden}

As mentioned earlier, the research Professor Isshiki is conducting for Sanden is done through his laboratory at Nihon University. However, Professor Isshiki also actively consults at the Sanden Laboratory. Professor Isshiki and his laboratory are responsible for helping to develop the seals, the regenerator and the heater head for a Sanden engine that is based on existing Sanden wobble-plate technology.

Sanden is pursuing the design, even without MITI funding, because they feel it will be inexpensive to manufacture. No expensive alloys are used, as the heater head is stainless steel. The engine was described by Professor Isshiki at the 1986 Intersociety Energy Conversion Engineering Conference. It is still in the early stages of development with low thermai and mechanical efficiencies. Overall efficiency is less than $10 \%$ and the mechanical efficiency of the system is only about $40 \%$. In addition, only one version of the engine has been constructed, and it is in the Sanden laboratory. The goal is to achieve an overall efficiency of $22 \%$. They would like to achieve $4000 \mathrm{rpm}$ for the system, but now operation is at about $1000 \mathrm{rpm}$. Although it is a $2 \mathrm{~kW}$ design, they have only achieved $1 \mathrm{~kW}$.

They are having a series of problems with the engine. In the heater head the flame was apparently missing much of the heat transfer surface. Professor Isshiki also feels the regenerator is not providing the desired efficiency. Another problem has been vibration. There is a pressure imbalance on the back side of the cylinder which is causing the swash plate to jump. They have been addressing this problem by adding balancing weights. 
A fourth problem Professor Isshiki mentioned was leakage around the piston rings.

\subsubsection{Ship Research Institute}

As mentioned previously, research on Stirling engines at the Ship Research Institute began over 10 years ago, in 1977, with the Marine Stirling Project sponsored by the Ministry of Transportation. - There appear to have been two stages to that project. The first involved the development of a T-type Stirling engine largely for test purposes and the second stage involved a very ambitious effort to develop a $200 \mathrm{hp}$ Stirling engine with a $155 \mathrm{~cm}$ diameter piston.

The T-type test engine is still being used in the laboratory of the Ship Research Institute for various component and regenerator tests. The $200 \mathrm{hp}$ engine project appears to have largely ended in fallure. The engine had large pumping losses, there was large friction in the rod seals, and efficiency was less than half of that expected. The net efficiency was less than $20 \%$ and the $P-V$ efficiency was $37 \%$. The project involved several major companies, inciuding Mitsubishi Heavy Industries and Daihatsu. The funding for the project came from both the Ministry of Transportation and from a technology promotion organization that received money from taxes on motor boat racing.

Currently, the two principal projects under way are the Tokyo Sanyo 2 kW Stirling engine project and general research using the T-type Stirling engine. Staff time is split about evenly between the two projects.

\subsection{PROFESSOR NISHIMOTO}

Currently, at Kanazawa University Professor Nishimoto is focusing his Stirling engine work on running full engine tests to identify ways to continue to improve cycle efficiency. All of the research funding comes from the university. 


\subsection{LITERATURE COMPARISON}

Results of the literature comparison are presented below by lab or professor.

\subsubsection{Mechanical Engineering Laboratory}

As the publications listed below indicate, much of MEL's recent work on its experimental engines has been published in English. The literature contains extensive performance data and descriptions of the MELSE II and the double-acting MELSE III engines. At the time of the interviews, nothing had been published regarding the new MELSE $V$ engine or the single-acting MELSE III.

- Azetsu, A., I. Yamashita, A. Tanaka and K. Suzuki. 1986 (English). "Experiments and Analysis of a Double-Acting Displacer Type Stirling Engine MELSE III." Presented at the 3rd International Conference on Stirling Engines, Rome, 1986.

- Azetsu, A., I. Yamashita, A. Tanaka and S. Yanagihara. 1984 (English). "Experiment of a Two-Piston Type Stirling Engine MELSE II, Analysis of Engine Performance." Presented at the 19th Intersociety Energy Conversion Engineering Conference, 1984.

- Mitsuda, A., Y. Yamashita, Y. Narimatsu, Y. Sugitani, K. Saito and I. Yamashita. 1985 (English). "Stirling Engine Research and Development in Japan." Presented at the 20th Intersociety Energy Conversion Engineering Conference, 1985.

- Yamashita, I., A. Azetsu, A. Tanaka and S. Yanagihara. 1984 (English). "Experiment of a Two-Piston Type Stirling Engine and Its Preliminary Analysis." Presented at the Second International Conference on Stirling Engines, Shanghai, 1984.

- Yamashita, I., M. Tanaka, K. Suzuki and S. Yanagihara. 1983 (Japanese). Theoretical and Experimental Studies on Stirling Engines. Technical Report of the Mechanical Engineering Laboratory, №. 128, Tsukuba Science Park, Japan.

The following report describing the results of mid-program testing of engines developed by manufacturers is only available in Japanese. The key summary table from it is in Appendix B. Dr. Yamashita is currently drafting a more critical review of the mid-program data, which he plans to publish in Japanese as part of the laboratory publication series. 
- Chukan Hyoka Hokoku Sho (Mid-Term Evaluation Report). March 1985. The Mechanical Engineering Laboratory, Tsukuba Science Park, Japan.

\subsubsection{Professor Isshiki}

As the list of publications below indicates, Professor Isshiki has been one of the most active researchers in the Stirling engine field in Japan. Professor Isshiki has a strong preference for publishing in the international literature. Consequently, most of his articles are available in English. His work is listed by affiliation: his own research at Nihon University (and before, from the Tokyo Institute of Technology) Sanden, the Ship Research Institute, Tokyo Sanyo and Asahi Glass.

Nihon University and Tokyo Institute of Technology

- Isshiki, N., and S. Moriya. 1986 (English). "Study on Internal Combustion Stirling Engine." Presented at the 3rd International Stirling Engine Conference, Rome, 1986.

- Moriya, S., and N. Isshiki. 1985 (Japanese). "Theoretical Calculation of Heat Regenerative Internal Combustion Engine." Presented at the 1985 Koriyama Meeting of JSME Tohoku Branch, Koriyama.

- Uchiyama, M., H. Ohta, A. Mitsuishi, T. Mitsune, M. Abiko, K. Iizuka, $\mathrm{N}$. Isshiki and K. Watanabe. 1985 (Japanese). "Study on Stirling Engine." Presented at the 15th Technical Meeting for Graduating Students of Japanese Society of Mechanical Engineers, Tohoku Branch, Tsuruoka, March 1985.

- Watanabe, K., N. Isshiki and A. Mitsuishi. 1985 (Japanese). "Experimental Study on a Small Hot Air Stirling Engine." Presented at the 1985 Koriyama Meeting of Japanese Society of Mechanical Engineers, Tohoku 8ranch, Koriyama, June 1985.

- Wen, 8. (Sandong University of Oceanology, PRC), N. Isshiki, M. Isshiki and T. Torizuka. 1984 (English). "Performance of Internal Combustion Stirling Engine." Presented at the 2nd International Conference on Stirling Engines, Shanghai, 1984.

Tokyo Institute of Technology

- Isshiki, N., G. Terada, K. Yoshikawa, H. Kojima and H. Hashimoto. 1983 (English). "Experimental Studies on Small Stirling Engines of Different Types." Presented at the 18th Intersociety Energy Conversion Engineering Conference, 1983. 
Sanden

- Isshiki, N., H. Kojima, K. Hashimoto and Y. Takei (Sanden). 1985 (English). "The Development of the Z-Type Stirling Engine and Its Application." Presented at the 20th Intersociety Energy Conversion Engineering Conference, 1985.

- Isshiki, N., H. Kojima, K. Hashimoto, Y. Takei and N. Kobayashi (Sanden). 1986 (English). "The Development of 2 Cylinder Z-Type Stirling Engine for $1 \mathrm{~kW}$ Generator." Presented at the 3rd International Stirling Engine Conference, 1986.

- Kojima, H., K. Hashimoto, Y. Takej (Sanden) and N. Isshiki. 1984 (English). "Small Stirling Cycle Hot Air Engines for Practical Use." Presented at the 2nd International Conference on Stirling Engines. Shanghai, 1984.

Ship Research Institute

- Isshiki, N., and S. Tsukahara (Ship Research Institute). 1982 (English). "On Marine Stirling Engine Development." Presented at the 17th Inter- society Energy Conversion Engineering Conference, 1982.

- Isshiki, N., S. Tsukahara, M. Kuwabara (Ship Research Institute) and H. Ohizumi (Yanmar Diesel Co.). 1980 (Japanese). "Study on Stirling Engine (2nd Report)." Journal of the Marine Engineering Society in Japan. Vol. 15, No. 10 .

- Isshiki, N., S. Tsukahara and S. Takahashi (Ship Research Institute). 1983 (English). "Study on Marine Stirling Engines." Presented at the International Symposium on Marine Engineering, Tokyo, October 1983.

- Kuwabara, M., S. Tsukahara (Ship Research Institute) and N. Isshiki. 1983 (Japanese). Study on Stirling Engine (9th Report). Presented at the 41st Technica! Meeting of the Ship Research Institute, May 1983.

- Tsukahara, S., M. Kuwabara (Ship Research Institute) and N. Isshiki. 1980 (Japanese). Study on Stirling Engine (6th Report). Presented at the 35th Technical Meeting of the Ship Research Institute, Vol. 35 , No. 180.

- Tsukahara, S., M. Kuwabara (Ship Research Institute) and N. Isshiki. 1985 (Japanese). Study on Stirling Engine (10th Report). Presented at the 45th Technical Meeting of the Ship Research Institute, May 1985. 


\section{Tokyo Sanyo}

- Isshiki, N., F. Terada and F. Yoshikawa (Tokyo Sanyo). 1984 (English). "Experiments on $2 \mathrm{~kW}$ Stirling Engine With Bayonet Type Heaters and Coolers." Presented at 2nd International Conference on Stirling Engines, Shanghai, 1984.

- Isshiki, N., K. Yoshikawa (Tokyo Sanyo), T. Nishiba, S. Tsukahara and M. Kuwabara (Ship Research Institute). "Development of $2 \mathrm{~kW}$ Stirling Engine." Presented at the 3rd International Stirling Engine Conference, Rome, 1986.

\subsubsection{Professor Nishimoto}

Professor Nishimoto of Kanazawa University has not published any of his Stirling engine work in English.

- Nishimoto, K., and H. Kitamoto. 1985 (Japanese). "Designing of Trial Stirling Engine and Its Performance Test." Transactions of the JSME, Series B. Vol. 51, No. 462.

- Nishimoto, K., and S. Naka. 1982 (Japanese). "Research Related to the Performance Analysis of Stirling Engines, Report 1, Regenerator Heat Transfer Rates and Engine Efficiency." Transactions of the JSME, Series. B. Vol. 48 , No. 434 .

- Nishimoto, K., and K. Ogura. March 1980 (Japanese). "Heat Input and Thermal Efficiency under Schmidt's Condition and Performance of No. 1 Test Engine." Memoirs of the Engineering School of Kanazawa University. Vol. 13, No. 1 .

\subsection{4 other}

One article from Professor Nakajima at the University of Tokyo was identified for this category of Stirling engine research.

- Nakajima, N., M. Hirata and K. Wada. 1983 (Japanese). "Study on Speed Control of Stirling Engine by Phase-Angle Variation." Journal of the Marine Engine Society in Japan. Vol. 17, No. 4. 


\subsection{LITERATURE COMPARISON OF PRIVATE SECTOR R\&D}

With the national and university laboratories specializing in the evaluation of components, the private companies have been given the task of developing entire Stirling engine systems. Four Stirling engines are being deveioped: 1) $30 \mathrm{~kW}$ swash-plate engine, 2) $3 \mathrm{~kW}$ displacer engine, 3) $3 \mathrm{~kW}$ two-piston engine, and 4) $30 \mathrm{~kW}$ crankshaft-type engine.

The initial two to three years of the project were directed at getting engines together and operating in order to meet their mid-term efficiency goals. This is reflected in the technical literature, with articles typically describing overall system performance.

With many of the mid-term goals met, the development effort then fo used on refining the designs, making the engines more manufacturable, and investigating more thoroughly the performance of components. Therefore, some articles more specifically describing component research have emerged over the past two years, and an increasing number of these articles most likely will be published until the program ends.

Descriptions of each of the four Stirling engine projects in the Stirling Engines for Wide Use Project are fairly well represented in the international literature. The overall program and program goals are generally decribed at presentations at every major conference that includes Stirling engines. At that level, the international (English) literature is not too different from the Japanese literature, which is not surprising since the manufacturers are ultimately competitors and will also be somewhat guarded with each other. For example, Aisin Sieki, the manufacturer with the largest program, has a very small number of publications, and most of those are very general and in English.

The Japanese literature does differ from that generally available in English in the technical specificity of the information. Although the managers at the NEDO and AIST offices tend to publish only very general articles describing the program, in both Japanese and English, there are two publications that are technically detailed. One is the English language 
summary of the four programs titled, The Development of Stirling Engine, which is published each year. Component performance data on each of the four engines are presented. In addition, an even more detailed evaluation of one of the engines is published each year, but this is only available in Japanese. This past year the engine described was the $3 \mathrm{~kW}$ engine being developed by Toshiba. This is included in an annual description of all NEDO projects titled, "Jigyo Hokokukai Bunrikai Yokoshu" (Collection of Manuscripts of the Reporting and Departmental Conference Regarding Current Projects).

Other examples can be found in the articles of the manufacturers. For example the article "Development of a Compact $30 \mathrm{~kW}$ Stirling Engine," published in the Sanyo Technical Review (Matsue et al. 1986) provides more detail about the component design than English language articles such as "Improvements of $30 \mathrm{~kW}$ Class Stirling Engine" (Terada et al. 1986), presented at the International Stirling Engine Conference this year Rome. Additionally, articles describing component experiments have appeared over the past few years in the Japanese literature and have not appeared in the English language literature. For example, Toshiba has presented an article, "A Friction and Wear Test for Piston Rings for a Two-Piston Stirling Engine," at a society meeting in 1985 (Hiraoka, Ogishima and Marumo 1985). Researchers at Mitsubishi Electric have also recently presented component studies of the combustor, heat exchanger and mechanical system at technical society meetings. Those meetings do not appear in the general literature data base, so being aware of these presentations is difficuit.

\section{AISIN SEIKI - $30 \mathrm{~kW}$ SWASH-PLATE ENGINE FOR A COMMERCIAL HEAT PUMP (N530A)}

- Ishizaki, Y. (University of Tokyo), M. Ogura (Tokyo Gas Co.) and S. Haramura, (Aisin Seiki). 1979 (English). "The Study of the Gas Heat Pump System Oriven by a Stirling Engine." Presented at the 14th Intersociety Energy Conversion Engineering Conference.

- Kondo, T., N. Haramura and H. Nakayama. 1981 (Japanese). "Performance Testing of Stirling Engine." Internal Combustion Engine. Vol. 20, No. 10 . 
- Momose, Y., and T. Watanabe. 1986 (English). "Testing Results of Stirling Engine NS30A." Presented at the 3rd International Stirling Engine Conference, Rome, 1986.

- Watanabe, T., K. Yamaguchi and Y. Momose. 1985 (English). "30 kW Stirling Engine." Presented at the 20th Intersociety Energy Conversion Engineering Conference, 1985.

- Watanabe, T., S. Yamaguchi, K. Yamaguchi, Y. Momose, S. Haramura, T. Kondo and Y. Ishizaki. 1982 (English). "50 kW Stirling Engine." Presented at the 17 th Intersociety Energy Conversion Engineering Conference, 1982.

\section{MITSUBISHI ELECTRIC - $3 \mathrm{~kW}$ DISPLACER ENGINE (NSO3M)}

- Fujiwara, M., K. Kawajiri, Y. Kazumoto, K. Tsuchino and Y. Nomaguchi. 1985 (Japanese). "Heat Transfer Characteristics of Stirling Engine Heat Exchanger." Presented at the Technical Meeting of Japanese Society of Mechanical Engineers' Thermal Engineering, November 1985.

- Fujiwara, M., Y. Kazumoto, K. Kawajiri, T. Tsuchino and T. Nomaguchi. 1984 (Japanese). "Heat Transfer and Pressure Drop Characteristics of Stirling Engine Heat Exchanger." Presented at the Technical Meeting of Japanese Society of Mechanical Engineers, Hokuriku Branch, November 1984.

- Fujiwara, M., Y. Kazumoto and T. Nomaguchi. 1981 (Japanese). "Experimental Study on Stirling Engine." Presented at the 242nd Technical Meeting of Japanese Society of Mechanical Engineers, Kansai Branch, November 1981.

- Fujiwara, M., Y. Kazumoto and Y. Nomaguchi. 1982 (Japanese). "Experimental Study on Stirling Engine (II)." Presented at the 57 th Technical Meeting of Japanese Society of Mechanical Engineers, Kansai 8ranch, March 1982.

- Kawajiri, K., M. Fujiwara, Y. Kazumoto, K. Tsuchino and T. Nomaguchi. 1984 (Japanese). "Experimental Study on Water-Piston Stirling Engine." Presented at the Technical Meeting of Japanese Society of Mechanical Engineers, Hokuriku-Shin-etsu Branch, November 1984.

- Kawajiri, K., Y. Kazumoto, M. Fujiwara, K. Tsuchino and T. Nomaguchi. 1985 (Japanese). "Optimization of Stirling Engine Heat Exchanger." Presented at the Technical Meeting of Japanese Society of Mechanical Engineers, Tohoku Branch, November 1985.

- Kazumoto, Y., M. Jujiwara and Y. Nomagushi. 1984 (English). "Effects of Drive Mechanism on Thermodynamic Performance of Piston-Displacer Type Stirling Engine." Presented at the 2nd International Stirling Engine Conference, Shanghai, 1984. 
- Koda, T., K. Taketo, Y. Yoshida, K. Kashiwamura and T. Honda. 1985 (Japanese). "Improvement of Thermal Efficiency on Displacer Type Stirling Engine (1st Report, Assessment Method of Mechanical Losses)." Presented at the Japanese Society of Mechanical Engineers' Technical Meeting on Thermal Engineering. November 1985.

- Koseki, H., M. Sakai and T. Nomaguchi. 1985 (Japanese). "Study on Stirling Engine Combustor, 1st Report, Characteristics of NO Emission." Presented at the Technical Meeting of Japanese Society of Mechanical Engineers, Tohoku Branch, November 1985.

- Nomaguchi, T., M. Fujiwara, Y. Kazumoto, K. Kawajiri and H. Koseki. 1985 (English). "Development of a $3 \mathrm{~kW}$ Class Stirling Engine for Heat Pump Use." Presented at the 20th Intersociety Energy Conversion Engineering Conference, 1985.

- Nomaguchi, T., Y. Kazumoto and M. Fujiwara. 1983 (English). "Determination of the Regenerator Effectiveness of an Actual Stirling Engine." Presented at the American Society of Mechanical Engineers/ Japanese Society of Mechanical Engineers Thermal Engineering Joint Conference, Vol. 3., March 1983.

- Nomaguchi, Y., M. Suganami, M. Fujiwara, M. Sakai, Y. Kazumoto, H. Koseki, K. Kawajiri, Y. Hisamori, K. Taketo, T. Yoshida, T. Koda and K. Kashiwamura. 1986 (English). "Progress on $3 \mathrm{~kW} \mathrm{Class} \mathrm{Stirling} \mathrm{Engine}$ and Heat-Pump System." Presented at the 21st Intersociety Energy Conversion Engineering Conference, 1986.

- Nomaguchi, T., T. Suganami, M. Fujiwara, M. Sakai, Y. Kazumoto, H. Koseki, K. Kaswajiri, K. Taketo, T. Yoshida, T. Koda and K. Kashiwamura. 1986 (English). "3 kW Class Stirling Engine and Heat Pump System." Presented at the 3 rd International Stirling Engine Conference, Rome, 1986.

\section{TOSHIBA - $3 \mathrm{~kW}$ TWO-PISTON ENGINE (NS03T)}

- Hiraoka, N., K. Ogishima and H. Marumo 1985 (Japanese). "A Friction and Wear Test of Piston Rings for a 2-Piston Stirling Engine." Presented at the Annual Meeting of Japanese Society of Lubrication Engineers, 1985.

- Kagawa, N., S. Nagatomo, M. Sakamoto, T. Komakine, L. Hongo and T. Sakuma. 1986 (English). "Performance Analysis and Improvement of a 3 kW Stirling Engine." Presented at the 21st Intersociety Energy Conversion Engineering Conference, 1986.

- Komakine, T., M. Sakamoto, S. Nagatomo, N. Kagawa, I. Hongo and T. Sakuma. "Performance of a $3 \mathrm{kw}$ Prototype Stirling Engine for a Gas Fired Residential Heat Pump." Presented at the 20th Intersociety Energy Conversion Engineering Conference, 1985. 
- Sakamoto, M. 1985 (Japanese). "Two Piston Stirling Engine For Residential Heat Pump." Shou Enerugi (Energy Conservation). Vol. 37, No. 1.

- Sakamoto, M., S. Nagatomo, T. Domakine, N. Kagawa, N. Hongo and T. Iwasaki. 1984 (English). "A Small Sized Stirling Engine for a Gas Fired Residential Heat Pump." Presented at the Second International Stirling Engine Conference, Shanghai, 1984.

- Sakamoto, M., S. Nagatomo, T. Harada and T. Araoda. 1985 (Japanese). "3 kW Stirling Engine for a Gas Fired Heat Pump." Toshiba Review. Vol, 40. No. 11.

\section{TOKYO SANYO - $30 \mathrm{~kW}$ CRANKSHAFT-TYPE ENGINE FOR A COMPACT ELECTRIC GENERATOR} (NS3OS)

- Matsue, J., R. Katono, H. Sekiya, M. Takamatsu and H. Kurita. 1986 (Japanese). "Development of a Compact $30 \mathrm{~kW}$ Stirling Engine." Sanyo Technical Review. Vol. 18, No. 1.

- Terada, F., T. Ishihara, J. Matsue and R. Katono. 1986 (English). "Improvement of $30 \mathrm{~kW}$ Class Stirling Engine." Presented at the $3 \mathrm{rd}$ International Stirling Engine Conference, Rome, 1986.

- Terada, F., T. Nakazato, H. Kurita, J. Matsue, H. Sekiya and M. Takamatsu. 1985 (English). "Development of the $30 \mathrm{~kW}$ Class Small Size Stirling Engine." Presented at the 20th Intersociety Energy Conversion Engineering Conference, 1985.

- Terada, F., T. Nakazato and J. Matsue. 1984 (English). "30-kW Class Small-Size Stirling Engine (NS30S)." Presented at the 2nd International Stirling Engine Conference, Shanghai, 1984.

\section{KAWASKI - FREE PISTON DESIGN}

- Inabe, M., Y. Doi, T. Suzuki, 0. Noro, M. Iwamoto and T. Yanamoto. 1986 (English). "The Development of Free-Piston Stirling Heat Pumps." Presented at the 3 rd International Stirling Engine Conference, Rome, 1986. 
-

. 
APPENDIX A

ADDRESSES OF INTERVIEW PARTICIPANTS 


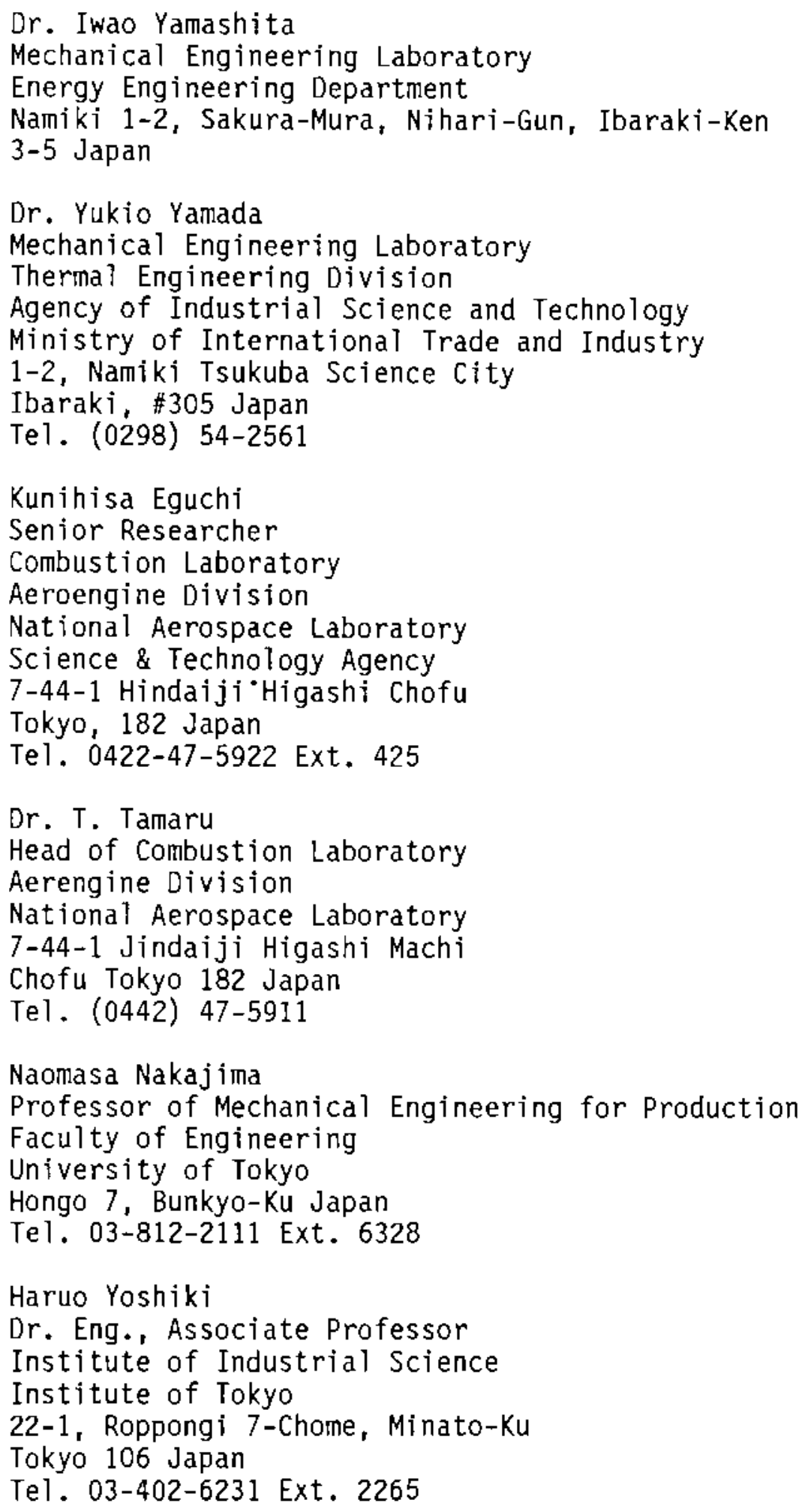


Or. Masaru Hirata

Professor, Department of Mechanical Engineering

University of Tokyo

Bunyko-Ku, Tokyo 113 Japan

Tel. 812-2111 Ext. 6416, 6419

Hydeya Miyabe

Or. Engineering, Professor

Mechanical Engineering Department

Meiji University

1-1-1 Higashimita Tama-Ku

Kawasaki 214 Japan

Tel. (044) 911-8181 Ext. 265

Dr. Iwane Fujii

Professor, Department of Mechanical Engineering

Faculty of Technology

Meiji University

Tamaku Kawasaki

Kanagawa 412 Japan

Tei. (044) 911-8181 Ext. 263

Etsuj i Miura

Engineering Manager

The Japan Refrigeration and Air Conditioning Industry Association

Kakai Shinko Bldg. 201

5-8 Shibakoen 3-Chome

Minato-Ku 105 Japan

Telex: 02422222 Jraia J

Fax: Tokyo (03) 438-0308

Te1: Tokyo (03) 432-1671 
APPENDIX B

PERFORMANCE SHEETS FROM MID-PROJECT TEST OF STIRLING ENGINES 
TABLE 8.1. Engine Test Results

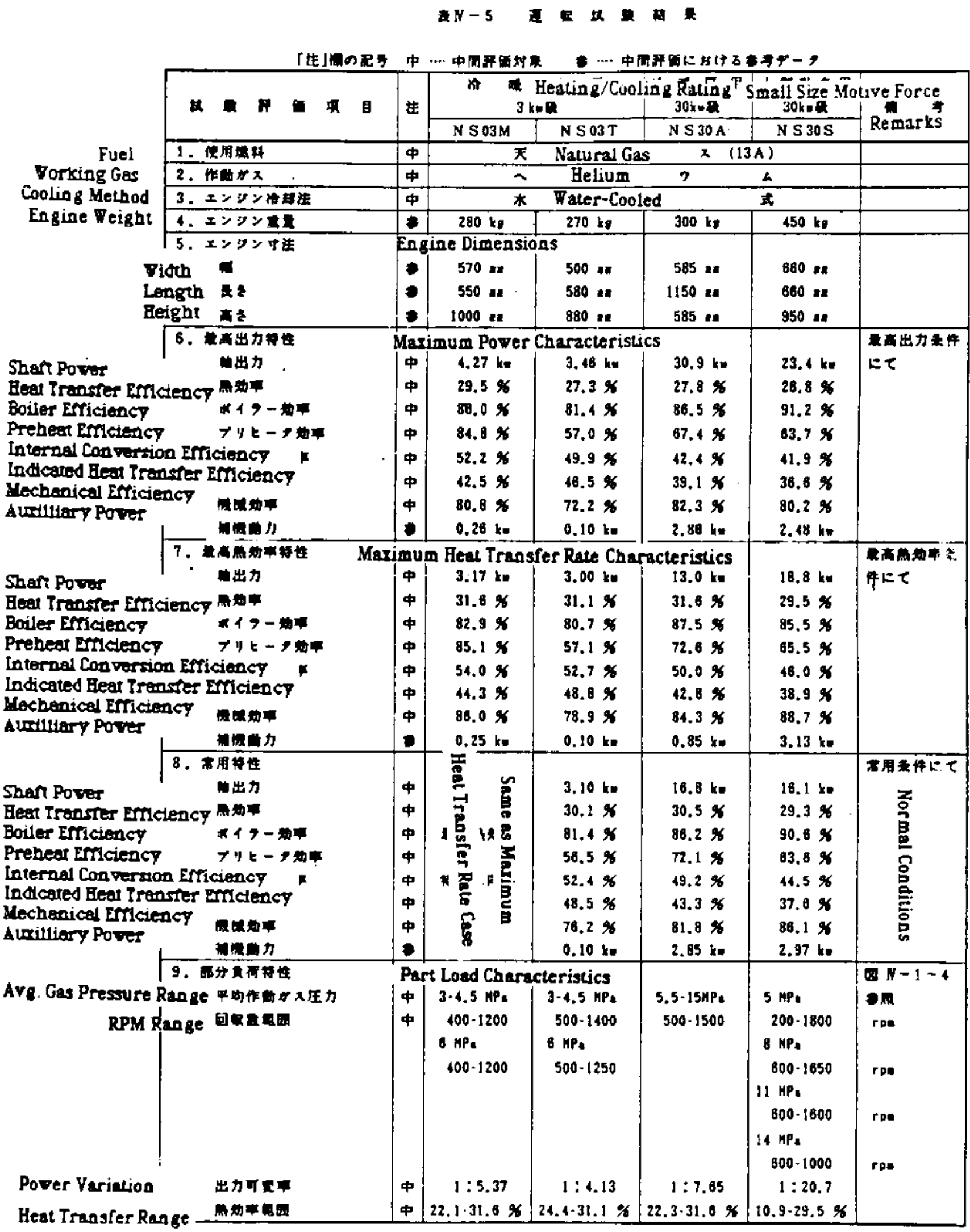

B. 1 
TABLE B.1. (contd)

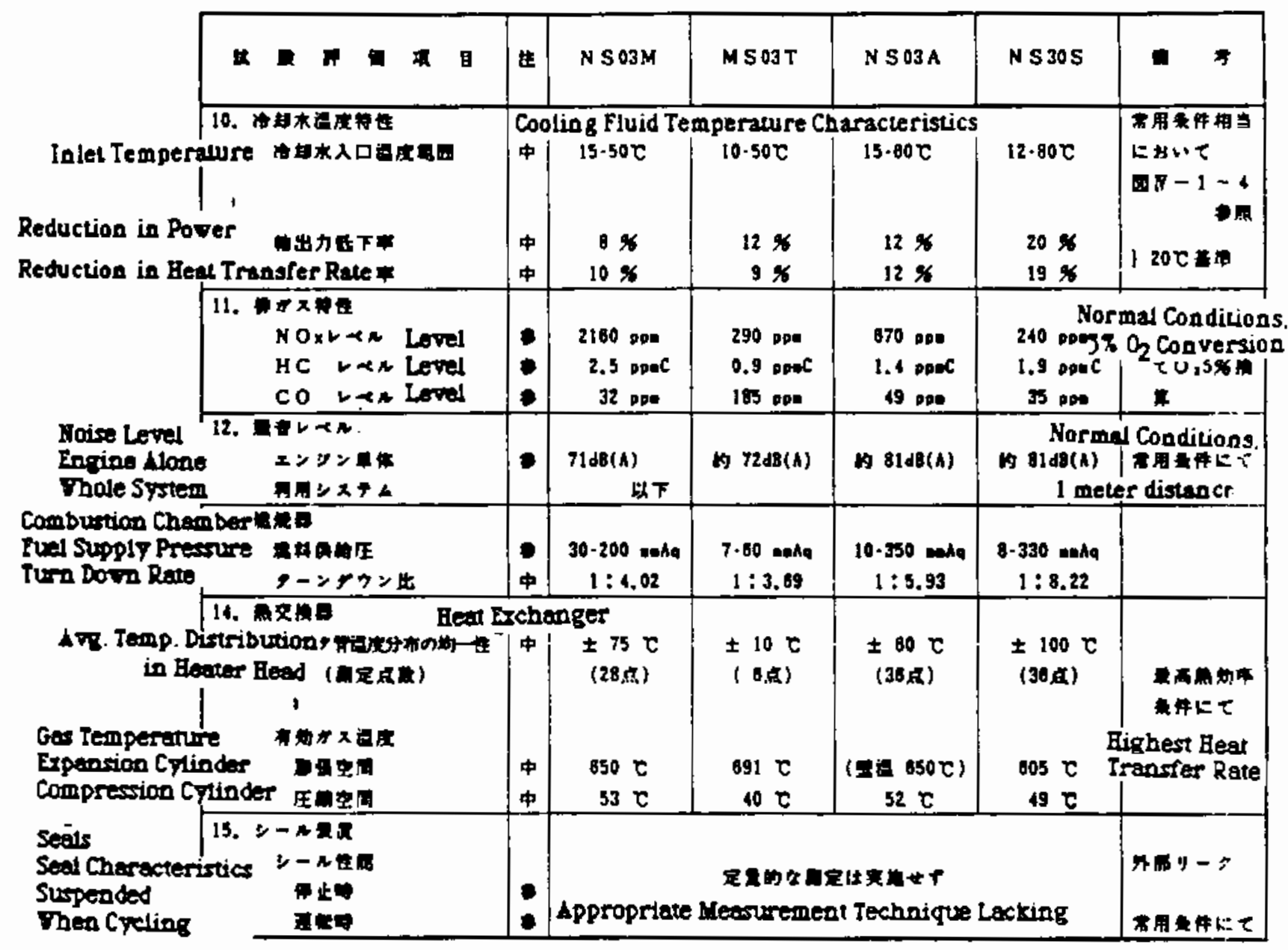


TABLE B.2. Wide Use Stirling Development Performance Goals

封

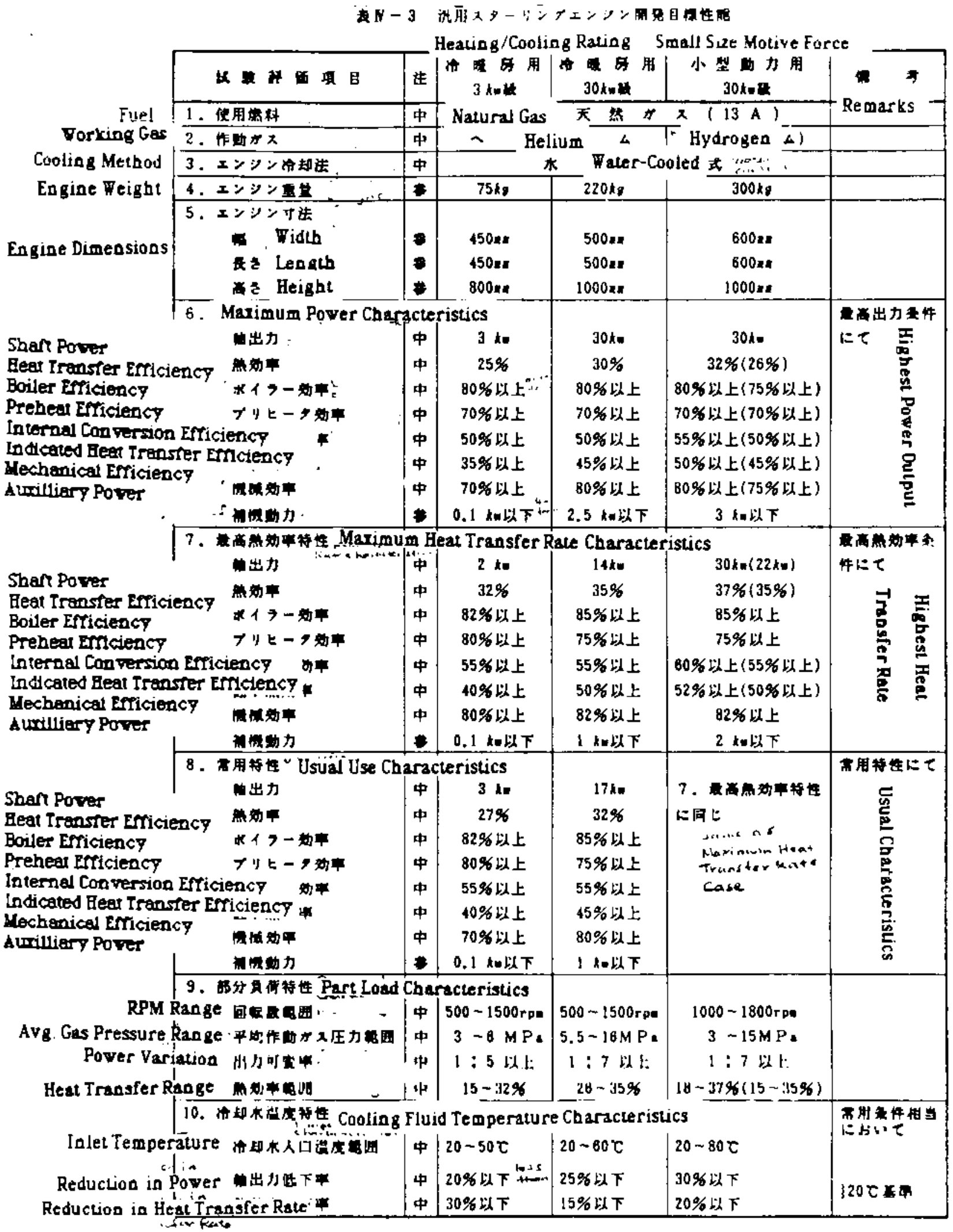


TABLE B.2. (contd)

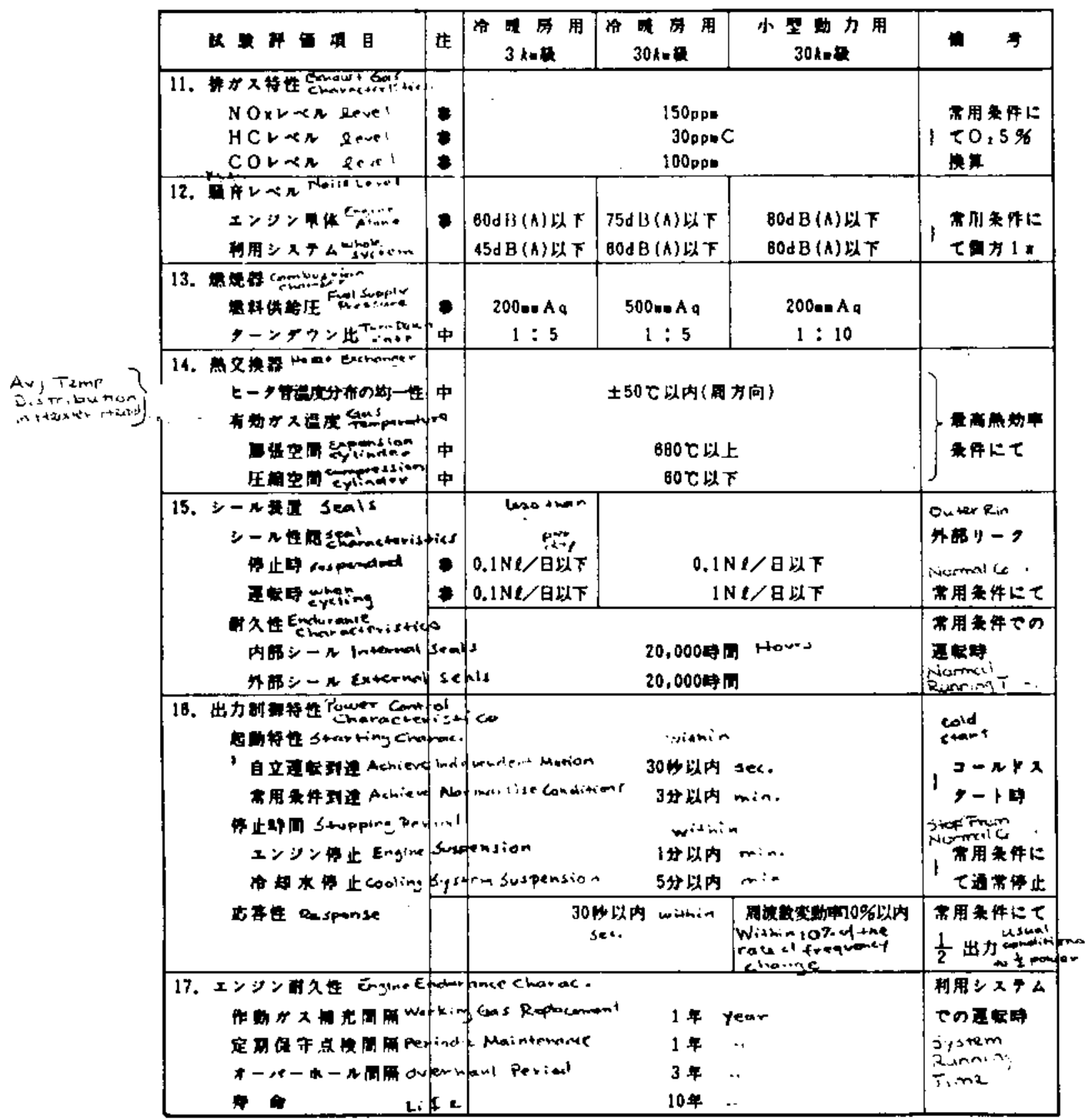

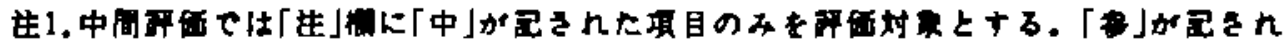

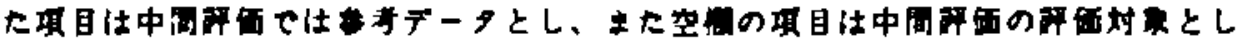
tr.

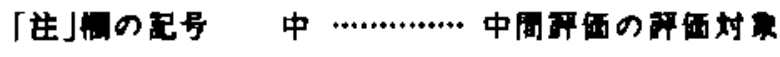

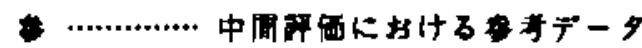

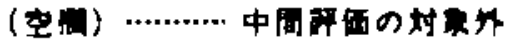

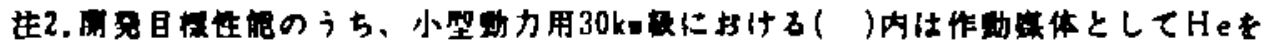
使用する揭合の目盾性能を示ナ。 


\section{DISTRIBUTION}

No. of

Copies

OFFSITE

30 DOE Technical Information Center

R. A. Ackerman

MT I, Inc.

968 Albany-Shaker Road

Lathan, NY 12110

W. Beale

Sunpower, Inc.

6 Byard Street

Athens, $\mathrm{OH} 45701$

D. Berchowitz

Sunpower, Inc.

6 Byard Street

Athens, $\mathrm{OH} 45701$

D. Beremand

NASA Lewis Research Center

21000 Brookparte Road

Cleveland, $\mathrm{OH} \quad 44135$

J. J. Brogan

CE -12

U.S. Department of Energy

1000 Independence Avenue

Washington, DC 20585

F. C. Chen

Oak Ridge National Laboratory

P.0. Box Y

Oak Ridge, TN 37831

A. Chesnes

CE -15

U.S. Department of Energy

1000 Independence Avenue

Washington, DC 20585
No, of

Copies

M. H. Chiogioji

$\mathrm{CE}-15$

U.S. Department of Energy

1000 Independence Avenue

Washington, DC 20585

J. Corey

MT I, Inc.

968 Albany-Shaker Road

Lathan, NY 12110

F. Creswick

Oak Ridge National Laboratory

P.0. Box Y

Oak Ridge, TN 37831

J. E. Dudenhoefer

NASA Lewis Research Center

21000 Brookparte Road

Cleveland, $\mathrm{OH} 44135$

A. Dybbs

Oepartment of Mechanical and Aerospace Engineers

Case Western Reserve University

University Circle

Cleveland, $\mathrm{OH} 44106$

J. Eberhardt

CE -12

U.S. Department of Energy

1000 Independence Avenue

Washington, DC 20585

W. Ernst

MT I, Inc.

968 Albany-Shaker Road

Lathan, NY 12110

P. Fairchild

Oak Ridge National Laboratory

P.0. Box Y

Oak Ridge, TN 37831 
No. of

Copies

R. Fiskum

CE -132

U.S. Department of Energy 1000 Independence Avenue

Washington, DC 20585

D. Gedeon

Gedeon Associates

Box 141A South Canaan Road

Athens, $\mathrm{OH} 45701$

B. Goldwater

MT I, Inc.

968 Albany-Shaker Road

Lathan, NY 12110

M. E. Gunn

$\mathrm{CE}-12$

U.S. Department of Energy

1000 Independence Avenue

Washingt on, DC 20585

B. Holtz

Argonne National Laboratory

$9700 \mathrm{~S}$. Cass Avenue

Argonne, $1 \mathrm{~L} 60439$

L. Johannson

Stirling Power Systems

7101 Jackson Road

Ann Arber, MI 48103

A. Maret

Gas Research Institute 8600 West Bryn Mawr Avenue

Chicago, IL 60631

J. P. Millhone

$\mathrm{CE}-13$

U.S. Department of Energy 1000 Independence Avenue

Washington, DC 20585

N. Nightingale

MTI, Inc.

968 Albany-Shaker Road

Lathan, NY 12110
No. of

Copies

D. Okimoto

U.S.--Northeast Asia Forum

$320 \mathrm{Galvez}$ Street

Stanford Uni versity

Stanford, CA 94305

P. Riggle

Stirling Technology Co.

2952 George Washingt on Way

Richland, WA 99352

P. D. Roach

Argonne National Laboratory

$9700 \mathrm{~S}$. Cass Avenue

Argonne, IL 60439

J. D. Ryan

CE -132

U.S. Department of Energy

1000 Independence Avenue

Washington, DC 20585

R. Samuels

MIT--Japan Science and Technology Program

Room E53-447

Massachusetts Institute of Technology

Cambridge, MA 02139

T. Simon

Departiment of Mechanical

Engineering

125 Mechanical Engineering Building

111 Church Street S.E.

Minneapolis, MN 55455

J. Slaby

NASA Lewis Research Center

21000 Brookparte Road

Cleveland, $\mathrm{OH} 44135$ 
No. of

Copies

J. L. Snith, Jr.

Cryogenic Engineering Laboratory

Massachusetts Institute of Technology

Cambridge, MA 02139

P. Sutton

CE -15

U.S. Department of Energy 1000 Independence Avenue washington, DC 20585

W. P. Teagan

A. D. Little, Inc.

Acorn Park

Cambridge, MA 02140

R. Tew

NASA Lewis Research Center

21000 Brookparte Road

Cleveland, $\mathrm{OH} \quad 44135$

D. Vaughn

U.S. Army Belvoir R\&D Center

Fort Belvoir, VA 22060

C. D. West

Oak Ridge National Laboratory

P.0. Box Y

Oak Ridge, TN 37831

M. White

Stirling Technology Co.

2952 George Washington Way

Richland, WA 99351

G. Wood

Route 1 Box 222

Albany, $\mathrm{OH} \quad 45710$

B. Ziph

Stirling Thermal Motors, Inc. 2841 Boardwalk

Ann Arber, MI 48104
No. of

Copies

FORE IGN

J. Calm

IEA Heat Pump Center

FIZ Karlsruhe

D 7514 EggensteinLeopoldshafen 2

FEDERAL REPUBLIC OF GERMANY

K. Holzapfel

IEA Heat Pump Center

FIZ Karlsruhe

D 7514 EggensteinLeopoldshafen 2

FEDERAL REPUBLIC OF GERMANY.

N. Isshik $i$

2-29-6 Kyoko

Setagayaku, Tokyo 156

JAPAN

A. Organ

University Engineering

Department

Cambridge University

Trumpingt on Street

Cambridge, CBZ IPZ

ENGLAND

G. Reader

Royal Naval Engineering College

Manaden, Plymouth

ENGLAND

G. Walker

Departiment of Mechanical

Engineering

University of Calgary

Calgary, $A B$

CANADA 
ONSITE

DOE Richland Operations Office

J. J. Sutey

No. of

Copies

35 Pacific Northwest Laboratory

R. C. Adams

Z. Antoniak

W. B. Ashton

G. J. Hane (5)

R. A. Hutchinson

B. M. Johnson

V. E. Lee (15)

B. A. Ross

T. J. Secrest

C. M. Stewart

Publishing Coordination MH (2)

Technical Report Files (5) 